\title{
An experimental investigation into the constant velocity water entry of wedge-shaped sections
}

\author{
T. Tveitnes ${ }^{a}$, A.C. Fairlie-Clarke ${ }^{\text {b,* }}$, K. Varyani ${ }^{\mathrm{c}}$ \\ a Chief Technical Officer FLEX LNG, 151-153 Farringdon Road, London EC1R 3AF, UK \\ b Department of Mechanical Engineering, University of Glasgow, 28 Shandon Crescent, Edinburgh EH11 1QF, UK \\ ${ }^{\mathrm{c}}$ Department of Naval Architecture and Marine Engineering, Universities of Glasgow and Strathclyde, 100 Montrose Street, Glasgow G4 0LZ, UK
}

\section{A R T I C L E I N F O}

\section{Article history:}

Received 20 December 2006

Accepted 29 June 2008

Available online 2 July 2008

Keywords:

Water entry

Water impact

Planing

\begin{abstract}
A B S T R A C T
Constant velocity water entry is important in understanding planing and slamming of marine vessels. A test rig has been developed that drives a wedge section with end plates down guides to enter the water vertically at near constant velocity. Entry force and velocity are measured. Analysis of the test data shows that the wetting factor is about 1.6 at low deadrise angles and reduces nearly linearly to 1.3 at $45^{\circ}$ deadrise angle. The added mass increases quadratically with immersed depth until the chines become wetted. It then continues to increase at a reducing rate, reaching a maximum value between $20 \%$ and $80 \%$ greater than at chine immersion. The flow momentum drag coefficient is estimated from the results to be 0.78 at $5^{\circ}$ deadrise angle reducing to 0.41 at $45^{\circ}$ deadrise angles. Constant velocity exit tests show that the momentum of the added mass is expended in driving the water above the surface level and that exit forces are low and equivalent to a drag coefficient of about 1.0-1.3. Considerable dynamic noise limits the accuracy of the results, particularly after chine immersion.
\end{abstract}

(c) 2008 Elsevier Ltd. All rights reserved.

\section{Introduction}

The constant velocity water entry of wedge-shaped sections is important as an aid to understanding two main phenomena: slamming and planing. This study is motivated by the latter, but the results also relate to the former since the water entry velocity of a large vessel may be only slightly reduced by slamming impact forces. In that case, constant velocity entry experiments provide a better simulation than a drop test, during which there is usually a rapid deceleration of the body on impact with the water.

The primary aim of the experimental programme reported in this paper was to provide a comparison with computational fluid dynamics (CFD) results and validation for a momentum theory for water entry forces described by Fairlie-Clarke and Tveitnes (2008). More generally, the aim of the experimental programme was to provide data that could help in predicting the dynamic behaviour of planing hulls in waves. The main objective was to obtain experimental data for the forces acting on wedge sections during constant velocity water entry, which are analogous to the forces acting on a planing hull section moving at constant speed through calm water. Additional wet chime oscillatory tests of the sections were planned that would enable estimates of added mass to be made that could be applied to planing hulls during oscillatory

\footnotetext{
* Corresponding author. Tel.: +441313371445.

E-mail address: tonyfc@blueyonder.co.uk (A.C. Fairlie-Clarke).
}

motions when the sections may not fully emerge from the water, and a further objective was to obtain some initial experimental data under constant velocity water exit conditions, which are important in predicting the dynamic behaviour of planing hulls in waves.

The authors do not know of any previous experiments where forces on wedge-shaped sections have been measured during constant velocity water entry and water exit. There have been a number of drop test experiments reported in the literature, but only a few of these are of interest in the present investigation because the majority have been carried out to investigate the peak pressures that occur during slamming; they do not include the condition of chine immersion nor do they separate out the force components during the impact. Bisplinghoff and Doherty (1952) performed drop tests with wedges having deadrise angle varying from $10^{\circ}$ to $50^{\circ}$. Accelerations were recorded and the added mass coefficients were extracted and compared with theory. These displayed considerable scatter, with comparatively low values at the lowest deadrise angle. They also observed the wetted widths and these were low compared with theory. Carcaterra and Ciappi (2004) performed drop tests with a symmetrical wedge section having a long length and no end plates. Their peak decelerations (proportional to force in a drop test) occurred before chine immersion, contained a significant amount of high frequency noise, and were about $15-20 \%$ below their theoretical values based on the linearised Wagner approach. Wu et al. (2004) performed drop tests with a symmetrical wedge section having a 
$0.6 \mathrm{~m}$ length, $0.2 \mathrm{~m}$ beam and no end plates. They presented acceleration results for $20^{\circ}$ and $45^{\circ}$ deadrise angles and compared these with a boundary element numerical simulation. There was significant noise in the acceleration signals and the peak deceleration occurred before chine immersion. There was good agreement between experiment and simulation for the $45^{\circ}$ deadrise angle section, but at $20^{\circ}$ deadrise angle the experiment results were up to $30 \%$ lower than the simulation results. No data were given on added mass and wetted width of the sections.

The paper describes the test rig design considerations, the experimental set-up and the test programme. A number of performance issues are discussed. The experimental results are presented; the hydrodynamic forces are isolated from the dynamic noise effects and compared with theory and with the results from the CFD simulations of Fairlie-Clarke and Tveitnes (2008).

\section{The test equipment}

\subsection{Design requirements}

Requirements for the test equipment were that it should interface with some existing model test sections having a beam of $0.6 \mathrm{~m}$ and deadrise angles from $5^{\circ}$ to $45^{\circ}$. Only those forces acting along the water entry axis were to be measured, and any forces acting on the endplates were to be isolated from the measurement.

An entry velocity of more than $1.0 \mathrm{~m} / \mathrm{s}$ was required so that the dynamic force component on the test sections at large deadrise angles would be significant compared to the buoyancy force. Velocities at the lower deadrise angles would be reduced, if necessary, to limit the entry forces. The design condition was taken as the water entry of the $10^{\circ}$ deadrise angle section at a velocity of $1.5 \mathrm{~m} / \mathrm{s}$. A CFD simulation showed that the water entry force would rise in $23 \mathrm{~ms}$ to a maximum of $4.5 \mathrm{kN}$, requiring a peak power of $6.8 \mathrm{~kW}$. The target was to keep velocity deviations to less than $1 \%$ during all experiments. A data sampling rate of up to $500 \mathrm{~Hz}$ would be needed to give at least 10 samples from initial entry to peak force.

\subsection{Description}

The test equipment is illustrated in Figs. 1 and 2, and comprised six main systems:

1. Test sections comprising a box and various wedge sections.

2. Model carrier for attachment of the test sections.

3. Drive and actuation system comprising a motor with controller and a system for transmission of motion to the model carrier.

4. Guide system to ensure a linear motion of the test section.

5. Sensors and a data acquisition system for measurement and recording of forces and velocities.

6. Video equipment to record wave motion at the water surface.

\subsubsection{Model test sections}

The test sections comprised a box section, which could be used on its own for zero deadrise angle tests, and symmetric wedge sections with deadrise angles $\beta$ of $5^{\circ}, 10^{\circ}, 15^{\circ}, 30^{\circ}$ and $45^{\circ}$ attached to the box section. The sections had length $L$ of $0.3 \mathrm{~m}$ and breadth $B$ of $0.6 \mathrm{~m}$, and the height of the box section was $0.3 \mathrm{~m}$. The box and the $15^{\circ}$ and $45^{\circ}$ wedges were constructed of PVC sheets, while the remaining sections were made of aluminium. Axial force load cells were mounted at the four top corners of the box section and provided the attachment to the model carrier. The masses of the sections are given in Table 1 .

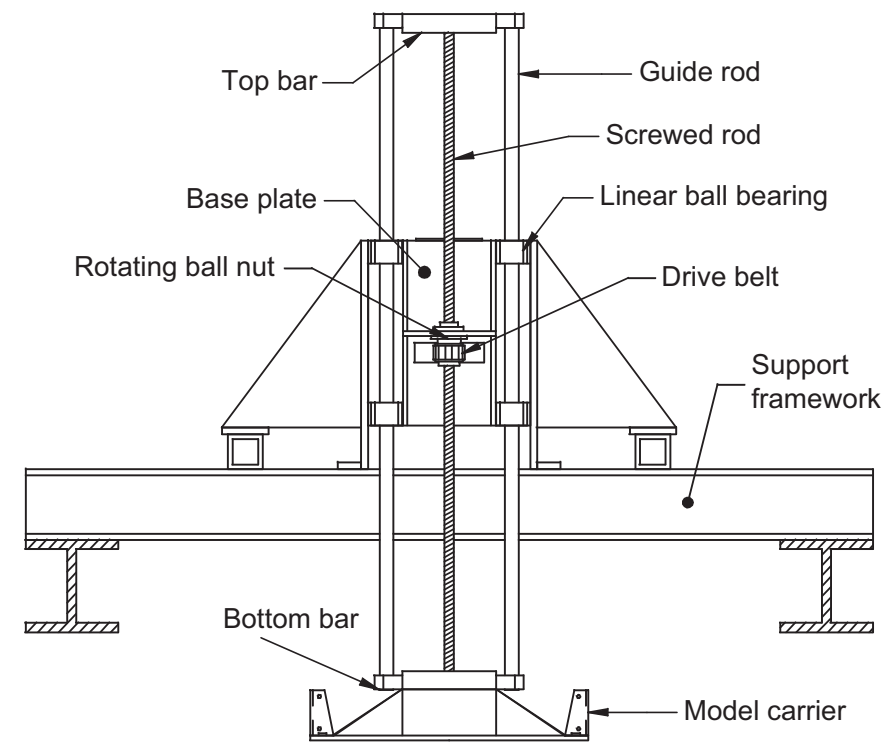

Fig. 1. Model drive and guide system.

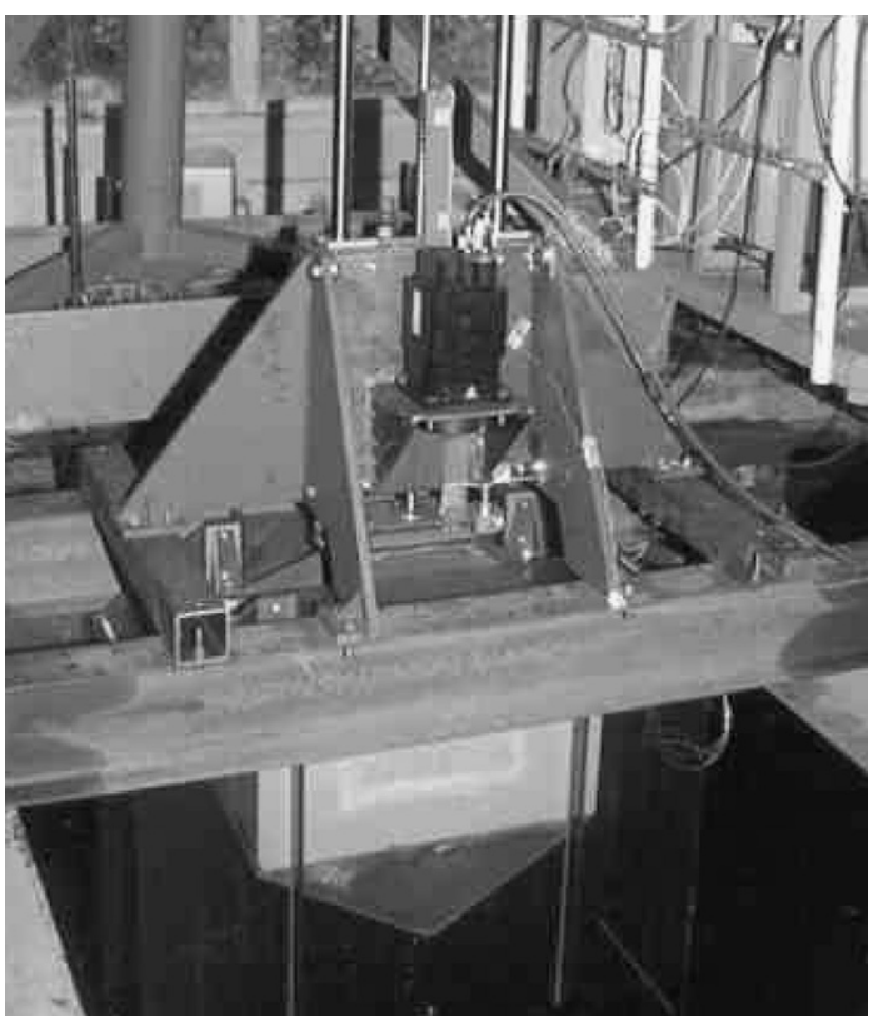

Fig. 2. Fully assembled test rig on support structure above the test tank.

\subsubsection{Model carrier and end plates}

The model carrier was manufactured from stiffened $10 \mathrm{~mm}$ steel plate and incorporated a bracket at each corner to provide mountings for transparent PVC sheets that acted as end plates to the model to promote two-dimensional flow. The PVC sheets were $1 \mathrm{~m}$ wide by $1 \mathrm{~m}$ deep and $10 \mathrm{~mm}$ thick with a chiselled bottom edge. Two vertical stiffeners were fitted to the outside of each sheet and the two sheets were tied together by a number of wires to reduce lateral deflections. The sheets were not attached to the model in any way, but travelled with it with a small clearance 
Table 1

Mass of test sections

\begin{tabular}{ll}
\hline Section & Mass $(\mathrm{kg})$ \\
\hline Box & 7.1 \\
$5^{\circ}$ wedge & 4.0 \\
$10^{\circ}$ wedge & 4.1 \\
$15^{\circ}$ wedge & 2.8 \\
$30^{\circ}$ wedge & 5.2 \\
$45^{\circ}$ wedge & 4.7 \\
\hline
\end{tabular}

measured as about $2 \mathrm{~mm}$ between the model and the sheet to reduce to a minimum any water flow between them.

The model carrier was bolted to the bottom bar of the travelling frame.

\subsubsection{Travelling frame}

The travelling frame comprised top and bottom horizontal bars that were fixed at their ends to two vertical guide rods and at their centres to the two ends of a vertical threaded drive rod. Each guide rod was free to run in a pair of vertically spaced linear ball bearings that were fixed to the test rig structure that straddled the experimental tank. The frame was thus free to travel vertically and could carry some side loading from the model, thus allowing, for example, water entry tests into waves.

\subsubsection{Drive and actuation system}

The travelling frame was driven vertically over a maximum travel length of $1 \mathrm{~m}$ by rotating a fixed ball nut through which the threaded drive rod passed. The precision ground ball screw had very high lead accuracy and zero axial play. Speeds of up to $5000 \mathrm{rpm}$ were possible corresponding to a linear screw velocity of $1.67 \mathrm{~m} / \mathrm{s}$. The axial load was limited by buckling considerations to a maximum of $7.4 \mathrm{kN}$.

The nut was driven via a timing belt (with a transmission ratio of $1.5: 1$ ) by a brushless synchronous servomotor delivering a torque of $8.5 \mathrm{~N} \mathrm{~m}$ at its rated speed of $3000 \mathrm{rpm}$, giving a linear vertical velocity of the drive rod of $1.5 \mathrm{~m} / \mathrm{s}$. The motor could operate at overload for up to $2 \mathrm{~s}$ to meet the peak torque requirement of $21.5 \mathrm{~N} \mathrm{~m}$.

With the expected rate of increase in the load for the design case, the suppliers of the servomotor estimated a speed deviation of less than a half percent.

The angular velocity of the motor was measured by a six-pole encoder with a $60 \mu$ s feedback loop. The resolution in terms of water entry velocity is $0.17 \mathrm{~mm} / \mathrm{s}$. With the high stiffness of the transmission components and zero backlash at the ball screw, the maximum error in measuring position of the wedge at entry to the water after a travel distance of $350 \mathrm{~mm}$ by integration of the velocity is estimated as $0.25 \mathrm{~mm}$.

\subsubsection{Sensors and data acquisition}

The four load cells gave a force capacity of $4000 \mathrm{~N}$ with a sensitivity of $0.02 \mathrm{mV} / \mathrm{N}$ load. The design case load of $4500 \mathrm{~N}$ would result in a slight, but safe, overload. In fact, the load never exceeded $4000 \mathrm{~N}$. Linearity and hysteresis were both within $0.03 \%$ of full load and the maximum error on calibration was $0.06 \%$.

A Strawberry Tree data acquisition system was used for simultaneous data logging of the four low voltage signals from the load cells and of the $10 \mathrm{~V}$ signal of motor speed from the servoamplifier. Data logging was controlled via PC software.

An analogue video camera was set up just above the water level to record the shape of the free surface during the tests.

\section{Test programme}

\subsection{Constant velocity water entry}

The test conditions are shown in Table 2. The choice of water entry velocities was a compromise between high velocities to maximise the hydrodynamic component of the total force for high deadrise angle sections and low velocities to reduce dynamic noise due to vibrations.

The servo amplifier was programmed to start each run from the travelling frame's top position. The acceleration was set as low as possible to minimise vibrations in the structure, with the entry velocity achieved just before initial entry. Constant velocity was then maintained until the whole of the wedge and approximately two-thirds of the box section was immersed. The next run commenced after a period of about $5 \mathrm{~min}$ to allow the water to calm down. Data recording started just before the entry motion program was engaged and stopped after the model had come to rest at the lowest position. The sample rate was varied from test case to test case between 100 and $500 \mathrm{~Hz}$ to give about 10 samples during the entry force rise time. Video film was taken during each test.

\subsection{Wet chine oscillation tests}

Wet chine oscillation tests were carried out with the $15^{\circ}$ and $45^{\circ}$ deadrise angle sections and also with the flat-bottomed box section. All three sections were oscillated with amplitude of $0.025 \mathrm{~m}$ about a mean level $0.2 \mathrm{~m}$ above the chines by applying a sequence of equal and opposite constant accelerations of $\sim 1.9 \mathrm{~m} / \mathrm{s}^{2}$ to give a maximum velocity of $\sim 0.3 \mathrm{~m} / \mathrm{s}$ at the mean level. The force measurements were recorded for about $10 \mathrm{~s}$ at a sample rate of $200 \mathrm{~Hz}$.

\subsection{Constant velocity water exit tests}

Constant velocity water exit tests were carried out with the $10^{\circ}, 15^{\circ}, 30^{\circ}$ and $45^{\circ}$ wedge sections at exit velocities of $0.48,0.72$, 0.72 and $0.94 \mathrm{~m} / \mathrm{s}$, respectively. The motion program was set so that the section moved at a low velocity of $0.05 \mathrm{~m} / \mathrm{s}$ to a depth at which the box section was about $80 \%$ immersed. After a delay of $2 \mathrm{~s}$, an upward acceleration was applied so that the constant exit velocity was achieved after $100 \mathrm{~mm}$ of travel, at which time the chine was still immersed by at least $100 \mathrm{~mm}$.

\subsection{Data processing}

The data acquisition system recorded the individual load cell readings and the model carrier velocity, which was derived from the angular velocity of the servomotor. Integration of the recorded velocity was used to track the position of the test section relative to its recorded initial position for each test.

The data logger was activated just before each test started. The sum of the force readings from the four load cells before motion started gave the weight of the test section mounted under the

Table 2

Water entry test conditions

\begin{tabular}{llllll}
\hline \multicolumn{7}{l}{ Deadrise angle } & & & \\
\cline { 2 - 6 } & $5^{\circ}$ & $10^{\circ}$ & $15^{\circ}$ & $30^{\circ}$ & $45^{\circ}$ \\
\hline Velocity (m/s) & 0.24 & 0.48 & 0.48 & & \\
Velocity (m/s) & 0.48 & 0.72 & 0.72 & 0.72 & \\
Velocity (m/s) & 0.94 & 0.94 & 0.94 & 0.94 & 1.19 \\
\hline
\end{tabular}


load cells. This weight was removed from the total force reading of all data sets. Thus, model weight is not included in any of the force data presented in this paper.

For each test case, four runs were performed with the same motion program to check the repeatability of the force readings. The results from the four runs compared well but there were some small time shifts (up to $10 \mathrm{~ms}$ ) due to the difficulty of precisely measuring the position of the model at the start point of each run. The results from the four runs were aligned in time as closely as possible before calculating the average force. Three out of the total of 48 runs showed spurious deviations and were not included in the calculation of the averages. Because of the finite sampling time, it is possible that the peak force was missed in any particular run, so the character of the peak was examined to determine the most likely peak force, usually the highest of the four measurements. The force measurements demonstrated good repeatability, with the variation of the individual measurements from the average of the four measurements for water entry up to $z / d=2$ being in the range of $1-3 \%$ of the peak force for each test. The force data (prior to applying the time shift) for four identical tests of constant velocity water entry are plotted in Fig. 3 as an example. All the force measurements presented in the paper are the sum of the four load cell outputs averaged over four identical test runs less the weight of the model.

\section{Results}

\subsection{Constant velocity water entry tests}

The data from these tests are presented in Fig. 4 where the water entry forces are plotted against the ratio of $z$ (the immersed depth of the apex of the wedge below the undisturbed water surface) to $d$ (the vertical height of the chine above the apex of the wedge). Each graph in the figure shows the recorded water entry force data points together with a plot of the water entry force obtained from a simulation of the test and a plot of the estimated hydrostatic force, both as described in Section 5.1.

Fig. 5 shows images captured from the video taken during the water entry tests with entry velocities of around $1.0 \mathrm{~m} / \mathrm{s}$. The images are not very clear, so the edges of the wedge sections, the undisturbed water level and the wave surface have been overlaid with lines for clarity.

\subsection{Wet chine oscillation tests}

The hydrodynamic force data for the wet chine oscillation tests are plotted in Fig. 6 together with the velocity signal computed from the motor speed and an estimate of the hydrodynamic force,

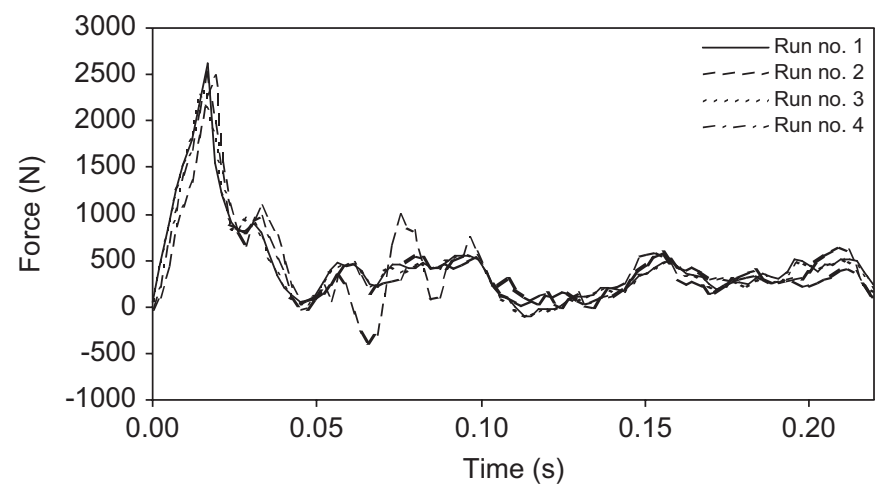

Fig. 3. Typical experiment recordings. calculated as a fit to the experimental data as described in Section 5.2. The hydrodynamic forces were extracted from the total recorded forces, which ranged from 300 to $500 \mathrm{~N}$, by subtracting the buoyancy force to the undisturbed water level and the inertial force to accelerate the mass of the model.

\subsection{Constant velocity water exit tests}

The recorded water exit fluid force data are plotted in Fig. 7 for the period after constant upward velocity was achieved. Also plotted are the calculated buoyancy force to the undisturbed water level and an estimate of the exit fluid force, calculated as a fit to the experimental data as described in Section 5.3. The force recorded at the load cells is the buoyancy force less the dynamic force resisting upward movement. Thus, the difference between the buoyancy force and the total force recorded gives the dynamic force resisting upward movement. Note that the immersion depth is plotted on a decreasing scale so that increase in time corresponds to moving from left to right in the figure.

Fig. 8 shows images captured from the video taken during the exit experiments. The edges of the wedge sections, the undisturbed water level and the wave surface have been overlaid with lines for clarity. The exit velocity for the $45^{\circ}$ wedge section was $0.94 \mathrm{~m} / \mathrm{s}$ and not $0.75 \mathrm{~m} / \mathrm{s}$ as indicated in the photograph.

\section{Analysis of experiment results}

\subsection{Water entry tests}

It can be seen in Fig. 4 that there is significant dynamic noise associated with the wedge water entry results. For the results to be useful, it was necessary to extract from the experimental measurements an estimate of the hydrodynamic forces acting during true constant velocity water entry. During the experiments, the dynamics of the wedge surface, the drive system and the fluid system all acted to create a high frequency vibration at the wedge/fluid interface resulting in the noise in the experimental measurements. A simulation of the experiments was performed using Simulink ( ${ }^{\circledR}$ The Maths Works Inc.) to try to isolate the actual experimental constant velocity hydrodynamic entry forces from the experiment measurements. The model is illustrated in Fig. 9. The dynamics of the motor and the stiffness of the drive belt were given in data from the manufacturers. The stiffness of the drive rod was calculated. The stiffness of the model carrier and of the load cells and model box were measured in a load test machine. All these elements had high stiffness, and it was suspected that the larger amplitude oscillations stemmed mainly from the flexing of the impact surfaces of the wedges, which were less stiff. The impact surfaces were supported only at their edges, so the stiffness was nonlinear, and each wedge was different. This stiffness was estimated for each test and was varied, along with the estimates of the parameters defining the entry forces, to obtain as good a visual fit as possible to the experiment data. The priority in finding a good fit to the data was to match the peak force point, then the rise and fall of the force in the range of $z / d=0-1.0$, then the mean force at large values of $z / d$ and finally the oscillations for $z / d>1$. Hydroelastic effects and lateral vibrations were not included in the simulation.

The entry forces were calculated in the simulation using the method described by Fairlie-Clarke and Tveitnes (2008). The total force is made up of the hydrostatic force, a residual gravity force due mainly to the work done to raise the water splash up, and a hydrodynamic force due to the rate of change of added mass momentum and of flow momentum. The initial entry force is 
a

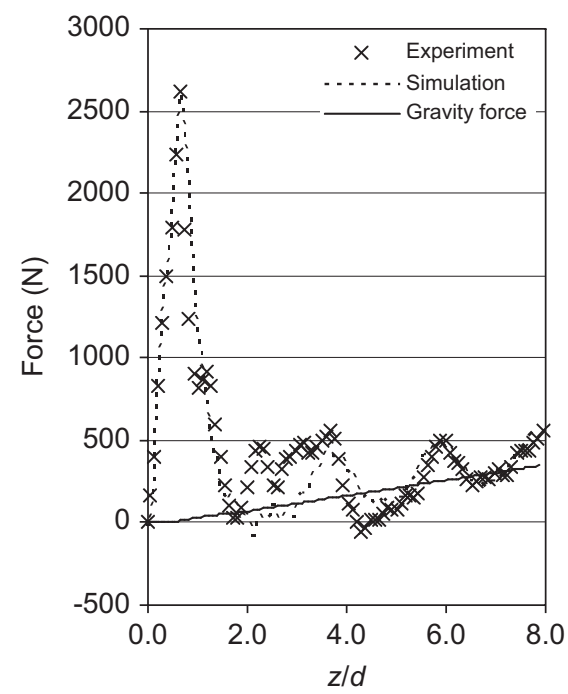

C

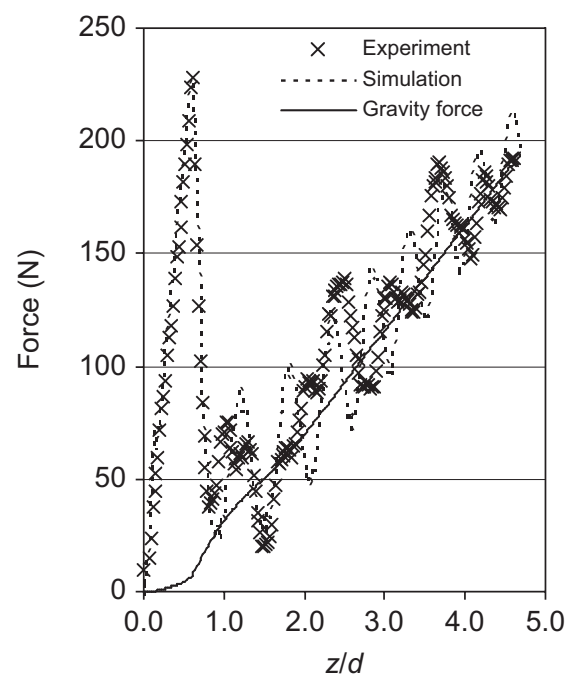

e

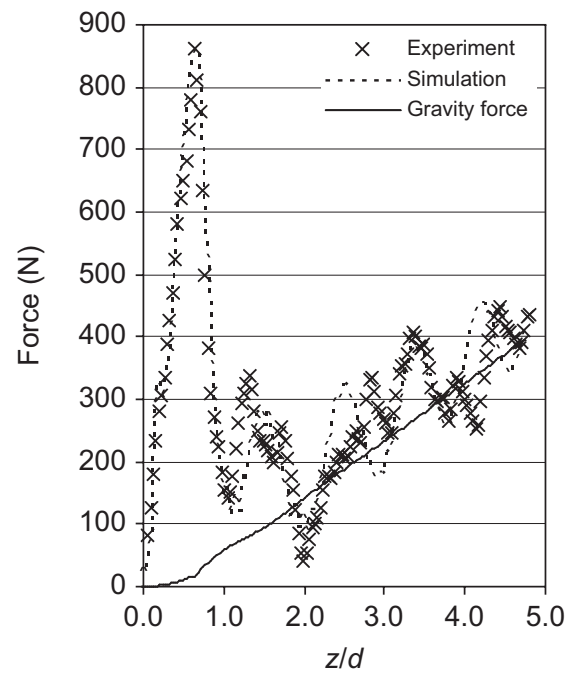

b

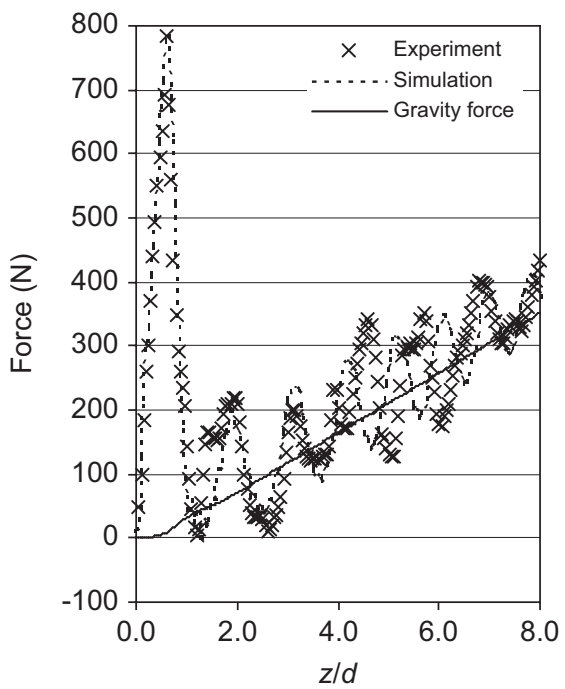

d

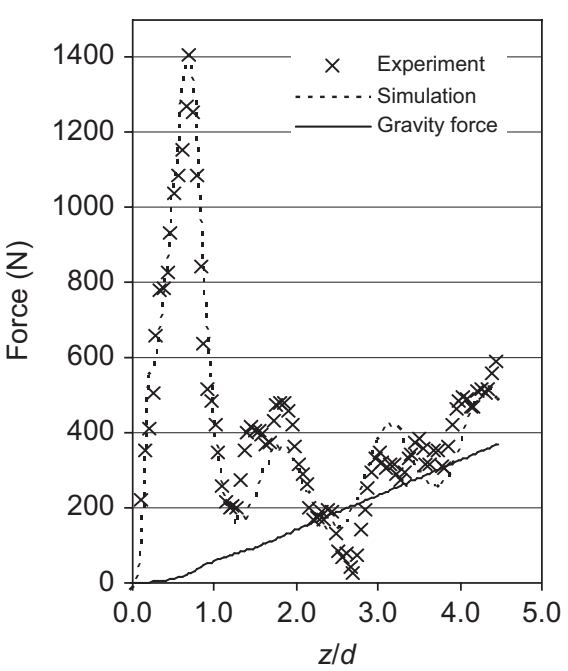

f

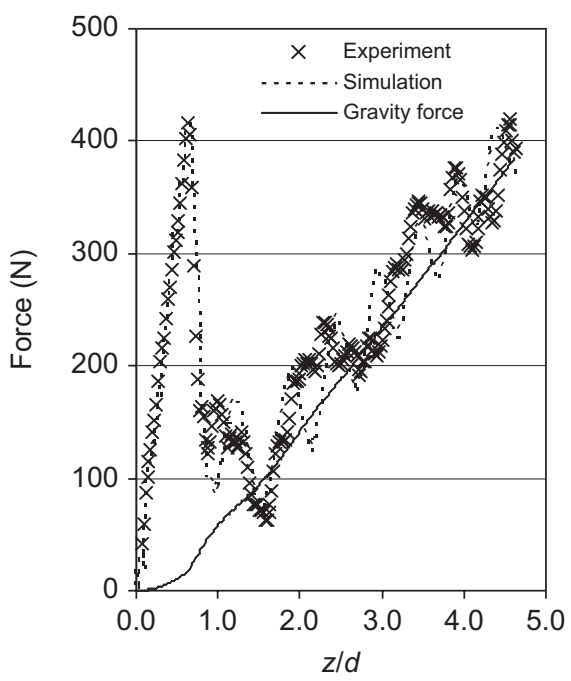

Fig. 4. Water entry test results (a) $\beta=5^{\circ}, v=0.94 \mathrm{~m} / \mathrm{s}$, (b) $\beta=5^{\circ}, v=0.48 \mathrm{~m} / \mathrm{s}$, (c) $\beta=5^{\circ}, v=0.24 \mathrm{~m} / \mathrm{s}$, (d) $\beta=10^{\circ}, v=0.94 \mathrm{~m} / \mathrm{s}$, (e) $\beta=10^{\circ}, v=0.72 \mathrm{~m} / \mathrm{s}$, (f) $\beta=10^{\circ}$, $v=0.48 \mathrm{~m} / \mathrm{s}$, (g) $\beta=15^{\circ}, v=0.94 \mathrm{~m} / \mathrm{s}$, (h). $\beta=15^{\circ}, v=0.72 \mathrm{~m} / \mathrm{s}$, (i) $\beta=15^{\circ}, v=0.48 \mathrm{~m} / \mathrm{s},(\mathrm{j}) \beta=30^{\circ}, v=0.94 \mathrm{~m} / \mathrm{s},(\mathrm{k}) \beta=30^{\circ}, v=0.72 \mathrm{~m} / \mathrm{s},(1) \beta=45^{\circ}, v=1.19 \mathrm{~m} / \mathrm{s}$. 
9

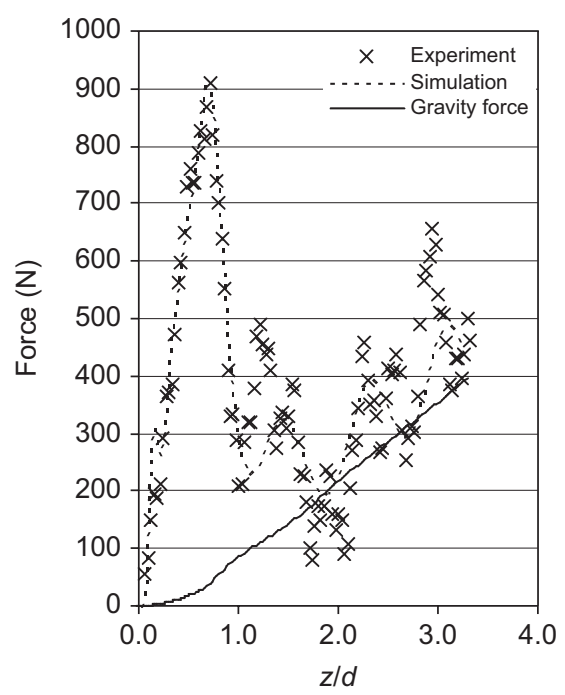

i

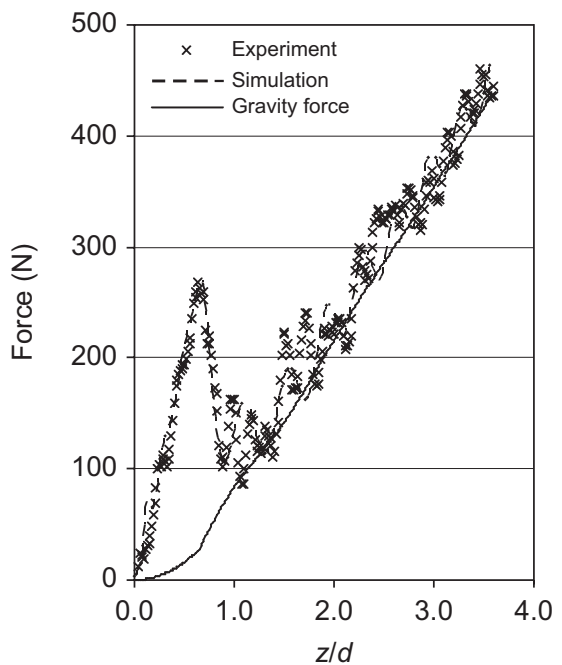

k

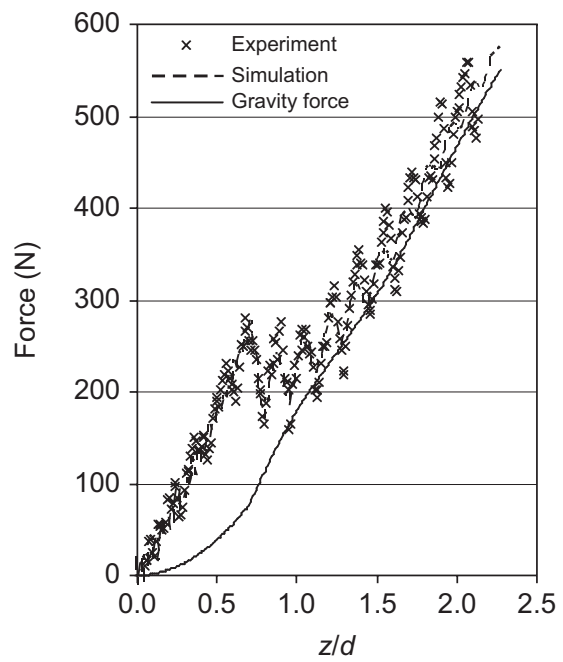

$\mathrm{h}$

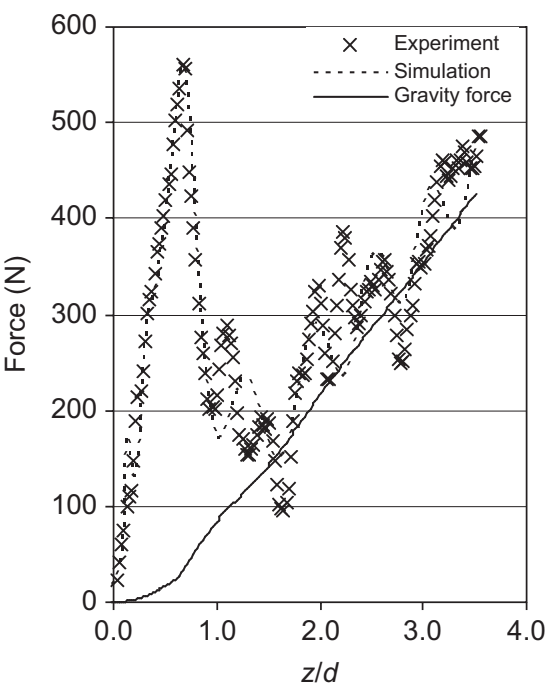

j

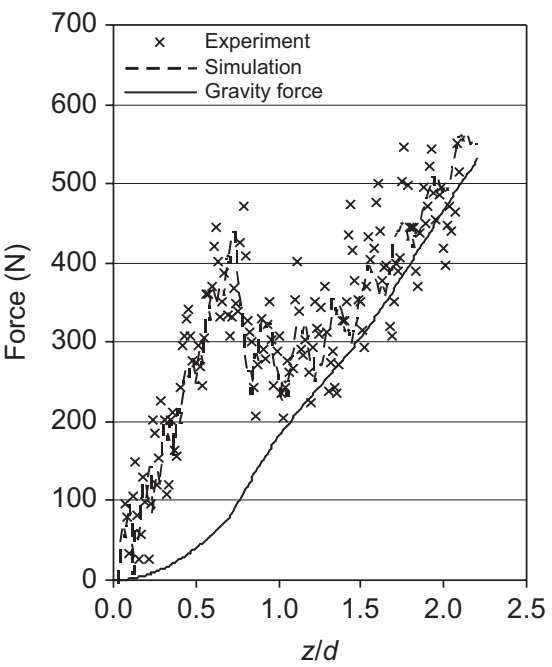

|

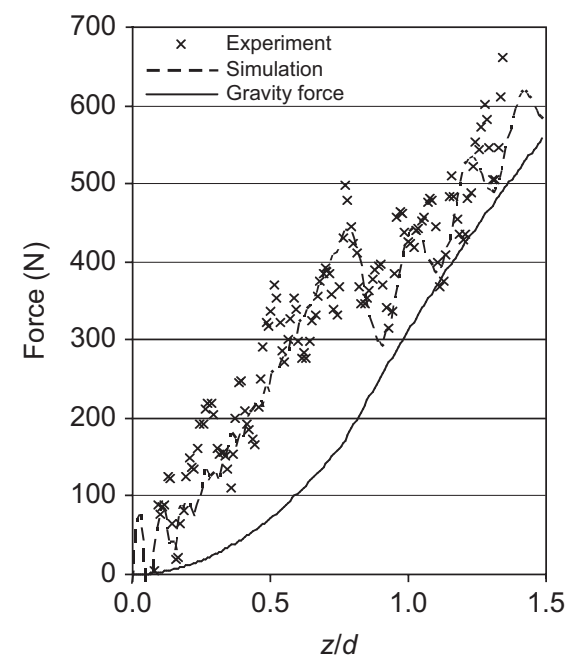

Fig. 4. (Continued)

dominated by the rate of change of added mass momentum and rises quickly until the chine becomes wetted. After chine wetting, the added mass and residual gravity forces decay, the hydrostatic force rises and the flow momentum force is assumed to have a constant value. The hydrostatic force was calculated as described below; the added mass was estimated from the initial force curve 
a

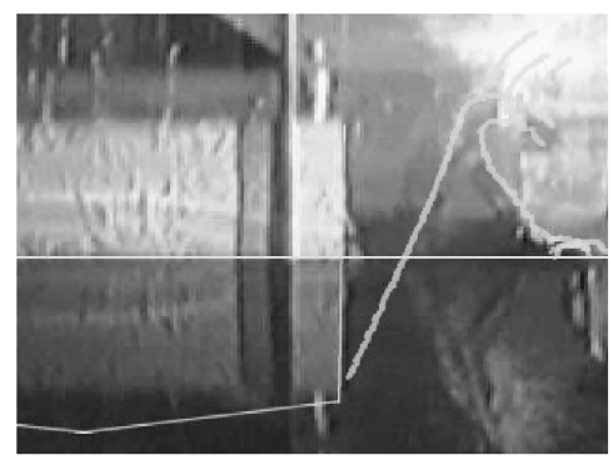

C

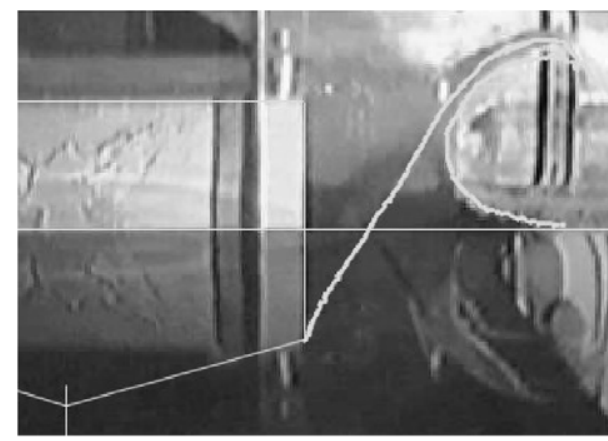

e

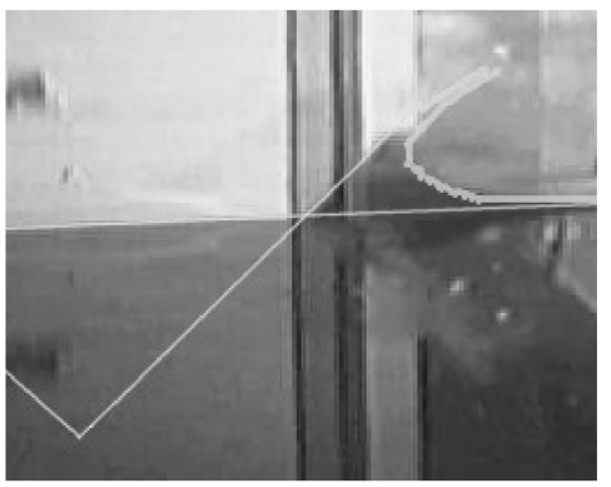

b

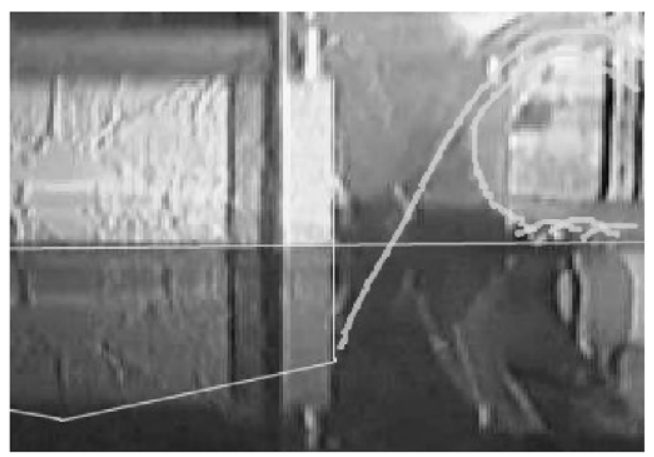

d

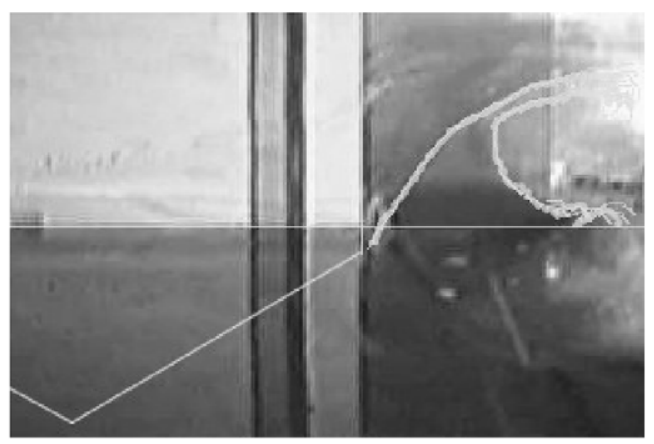

f

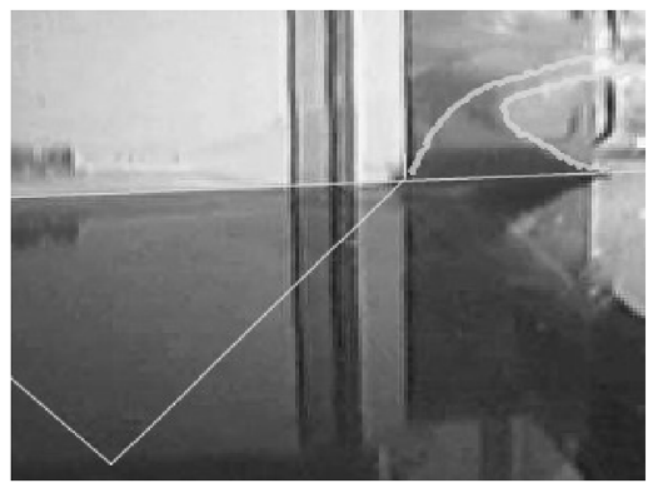

Fig. 5. Images of water entry at $v=1.0 \mathrm{~m} / \mathrm{s}$. (a) $\beta=5^{\circ}$, (b) $\beta=10^{\circ}$, (c) $\beta=15^{\circ}$, (d) $\beta=30^{\circ}$, (e) $\beta=45^{\circ}$, (f) $\beta=45^{\circ}$.

slope; the wetting factor $W F$ (defined as the ratio of the wetted width of the section to its width at the undisturbed surface of the water) was estimated from the limit of similarity conditions; while the decaying added mass, the residual gravity force and the flow momentum force were varied together to obtain a good visual fit to the data after chine immersion.

Fig. 10 shows as an example the build up of the force components in the simulation of the $10^{\circ}$ deadrise angle wedge entering the water at $0.94 \mathrm{~m} / \mathrm{s}$. The gravity force includes the basic hydrostatic force and the residual gravity force. $F_{\mathrm{fm}}$ is the flow momentum force and the total force is the sum of the gravity and $F_{\mathrm{fm}}$ forces together with the force due to rate of change of the added mass momentum. All these forces are calculated using the instantaneous values of wedge immersion and entry velocity. The 'simulation' curve also includes the force oscillations due to the vibrations of the wedge model mass and of the added mass (as calculated from the experiment data) that are assumed to follow the vibrations of the wedge impact surface, the velocity of which is also shown in the figure. Bereznitski (2001) states that if the rise time of the force is less than twice the natural period of the structural oscillations then hydroelasticity may be significant in determining the structural response. Thus, a full analysis of the $5^{\circ}, 10^{\circ}$ and $15^{\circ}$ wedge entries should include hydroelasticity, but this was beyond the scope of the present study. Possible consequences of this and other possible sources of error in the simulation are discussed in Section 6.

Fairlie-Clarke and Tveitnes (2008) show that during the chines dry phase of water entry, the added mass can be expressed as

$m_{\mathrm{a}}=C_{\mathrm{m}} \rho \frac{\pi}{2} L y_{\mathrm{w}}^{2}$,

where the wetted width $y_{\mathrm{w}}=W F y, y=z / \tan (\beta), z$ is the immersion of the apex of the wedge below the undisturbed water level, $L$ is the length of the wedge, $W F$ is the wetting factor, $C_{\mathrm{m}}$ is the added mass coefficient and $\rho$ is the density of the water.

Values for WF were set in the simulation so that the value of $z / d$ at which the peak force occurred matched that in the 
a

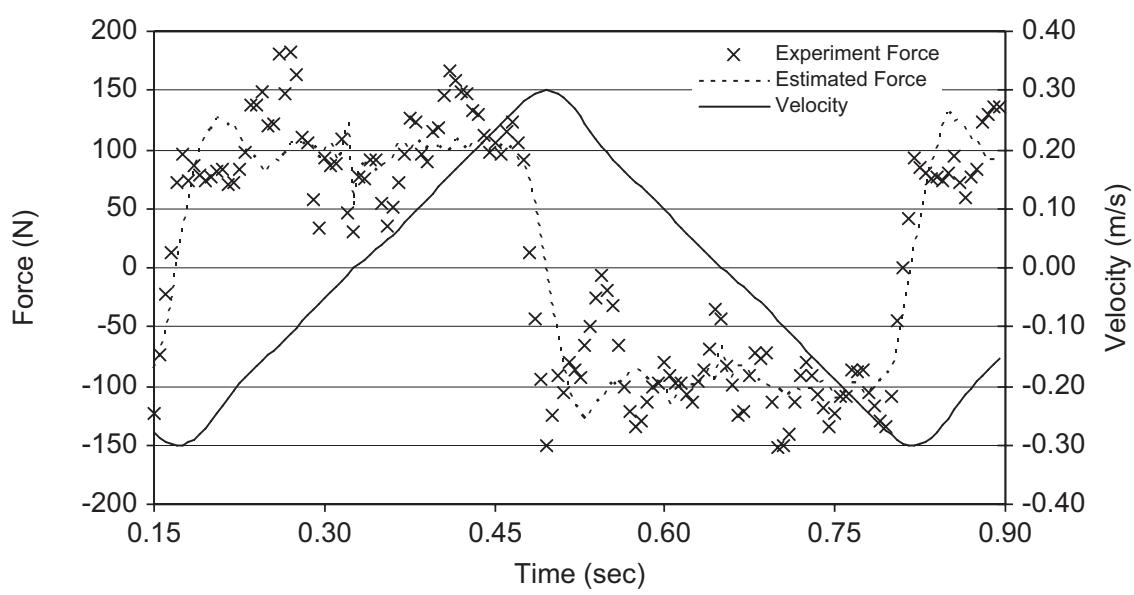

b

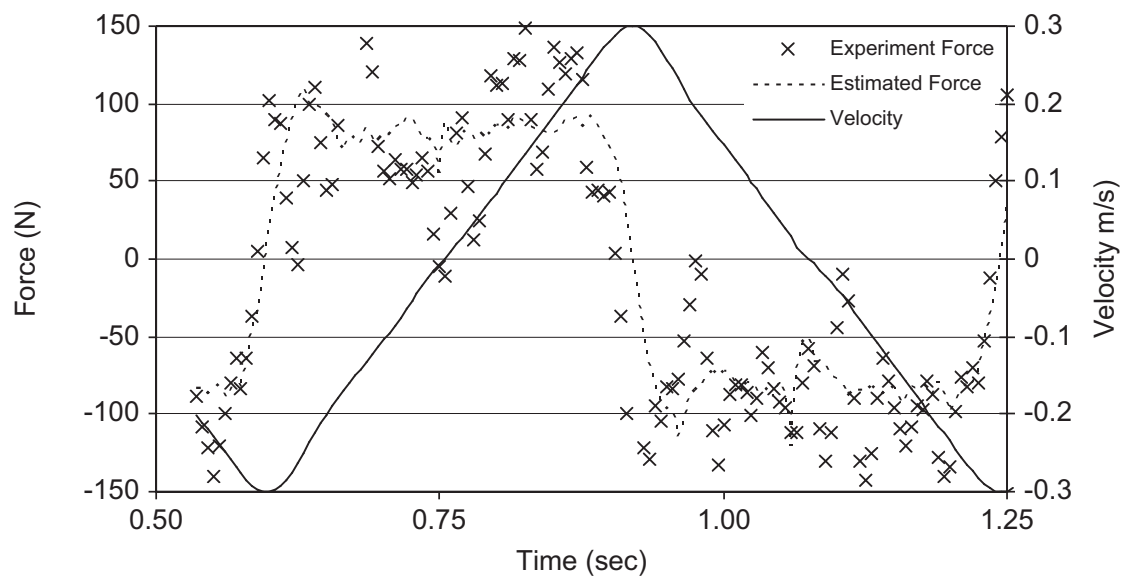

C

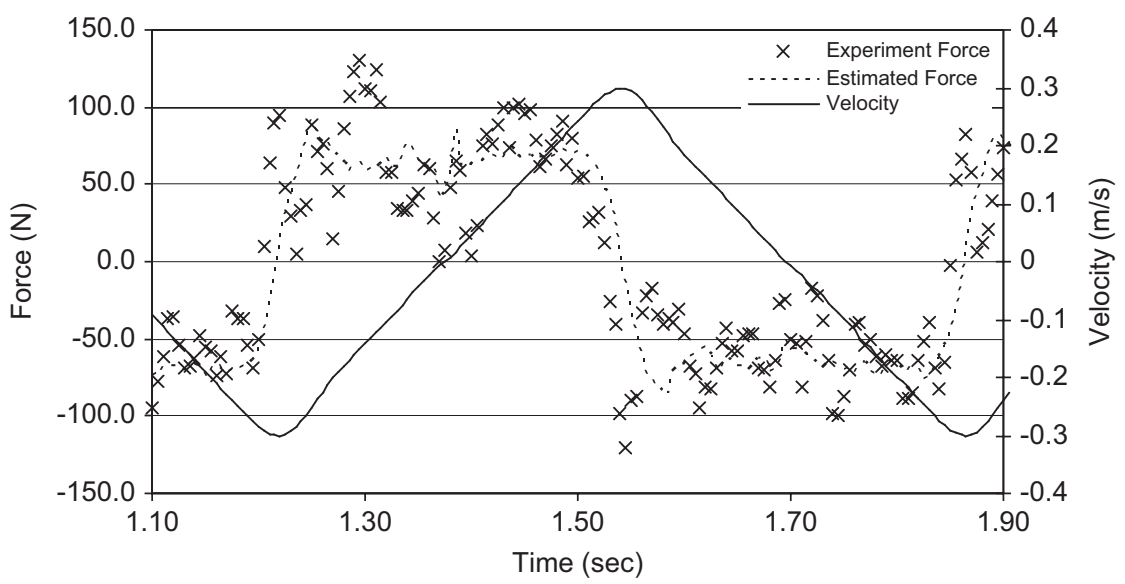

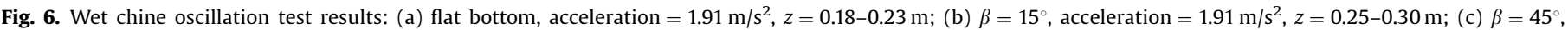
acceleration $=1.91 \mathrm{~m} / \mathrm{s}^{2}, z=0.48-0.53 \mathrm{~m}$.

experimental results. These values are plotted in Fig. 11 together with some theoretical estimates. Theoretical estimates of water entry forces based on the asymptotic assumption adopt a constant value of $W F=\pi / 2$ as derived by Wagner (1932), whereas in the similarity solution of Zhao and Faltinsen (1993) and in solutions by Vorus (1996) and by E. Band (reported by Payne, 1993), WF varies with the deadrise angle as shown in Fig. 11.

Values for $C_{\mathrm{m}}$ (Fig. 12) were set in the simulation to match the slope of the rising force curve in the experimental results after subtracting the gravity force and flow momentum drag force estimates.

The gravity force comprises the hydrostatic force, calculated by taking the hydrostatic pressure relative to the undisturbed water level and integrating over the wetted area of the wedge, and a residual gravity force that arises mainly because of the work that must be done against gravity to raise the water splash up. FairlieClarke and Tveitnes (2008) derive an empirical expression for the residual gravity force from the CFD simulations. This is given as a 
a

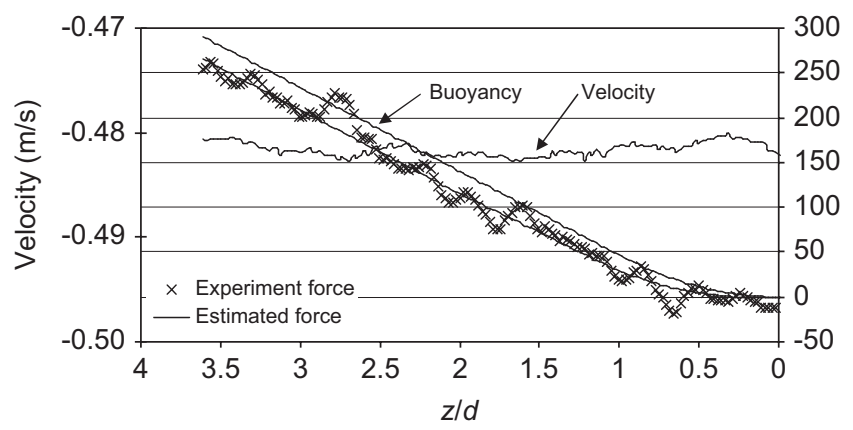

b

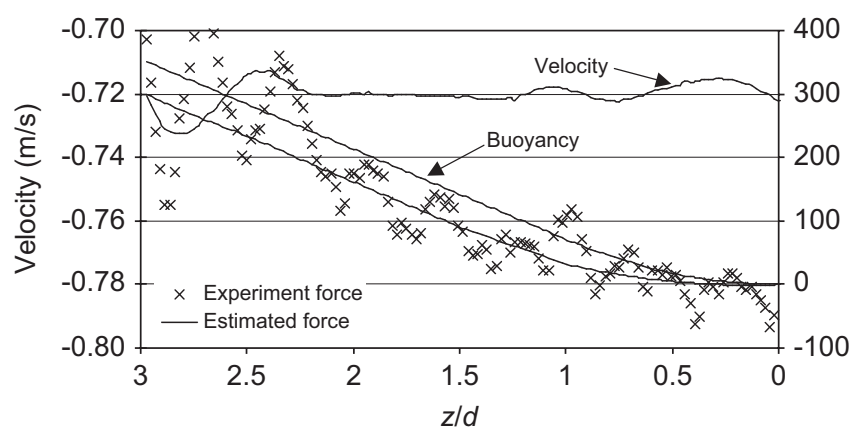

C

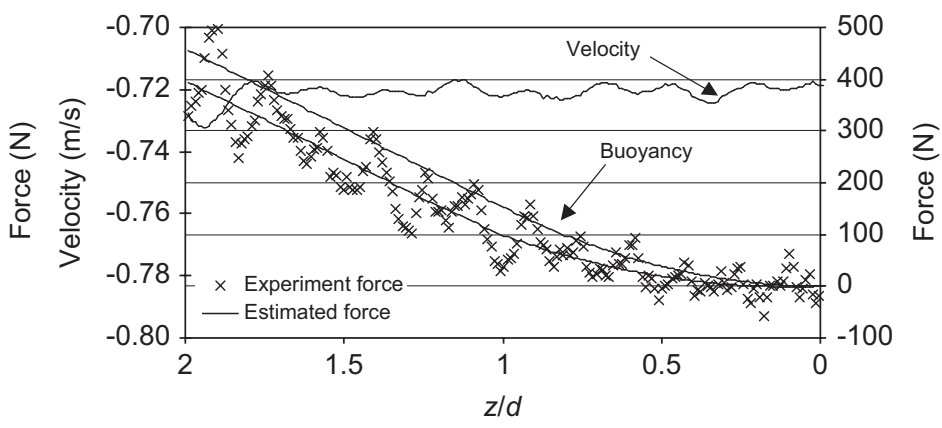

d

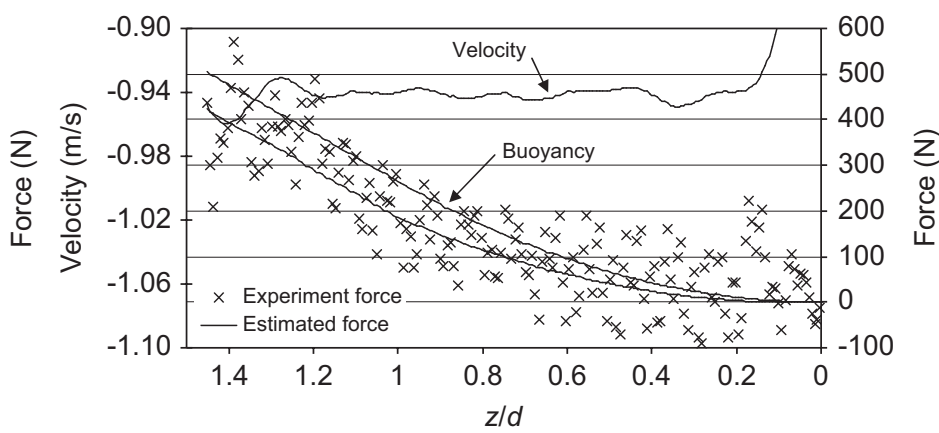

Fig. 7. Constant velocity water exit test results. (a) $\beta=10^{\circ}$, (b) $\beta=15^{\circ}$, (c) $\beta=30^{\circ}$, (d) $\beta=45^{\circ}$.

a

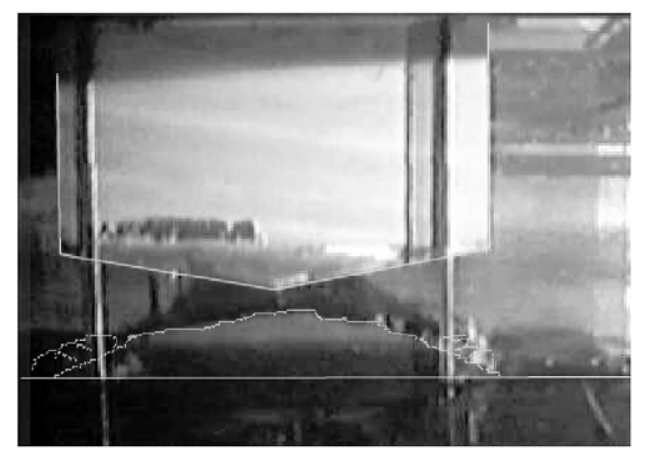

C

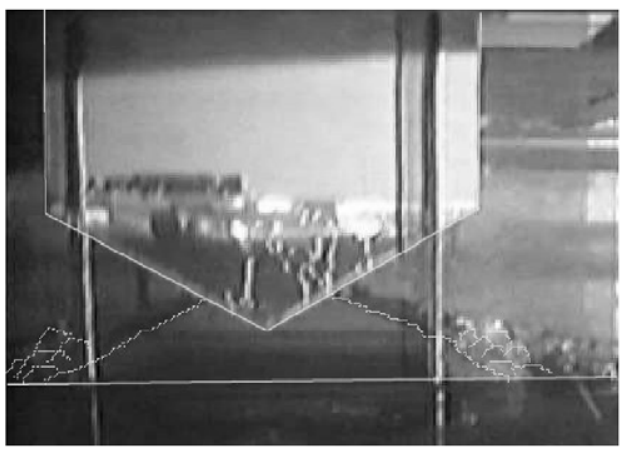

b

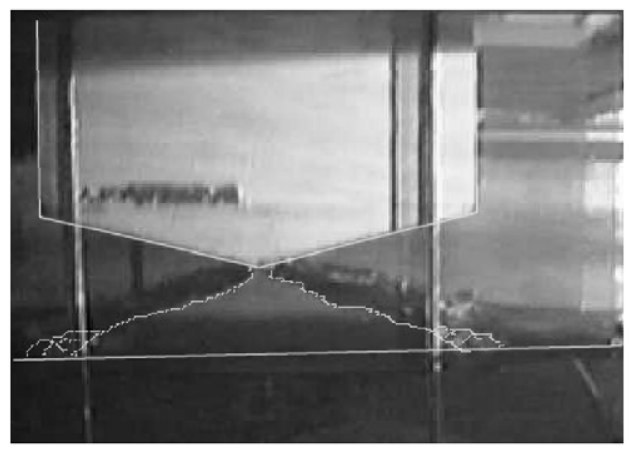

d

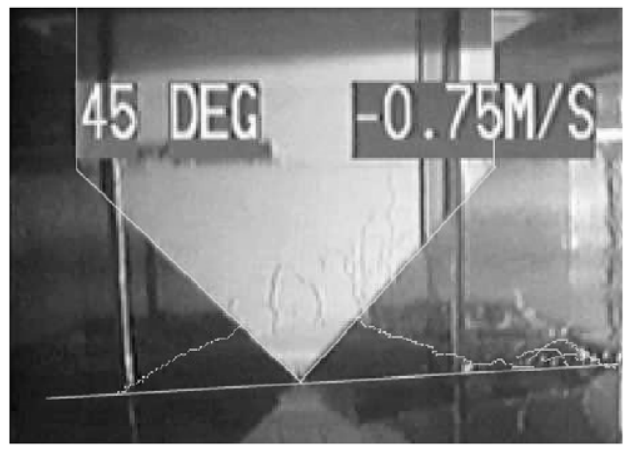

Fig. 8. Video images of constant velocity water exits. (a) $\beta=10^{\circ}$, (b) $\beta=15^{\circ}$, (c) $\beta=30^{\circ}$, (d) $\beta=45^{\circ}, v=1.0 \mathrm{~m} / \mathrm{s}$, not $0.75 \mathrm{~m} / \mathrm{s}$.

force coefficient $C_{\mathrm{gr}}$ non-dimensionalized on the static buoyancy of the wedge at depth $z$ :

$C_{\mathrm{gr}}=k_{1} \times\left[1+\cos \left(k_{2} G\right)\right] \exp \left(-G^{2}\right)$, where $G=\max (0,(z / d)-(2 / \pi))$ and values of $k_{1}$ and $k_{2}$ obtained from the CFD simulations are as shown in Table 3. These values of $k_{2}$ were used directly in the current simulation while $k_{1}$ was varied to give a good visual fit to the experiment data after chine immersion. 
The flow momentum drag force is given by Fairlie-Clarke and Tveitnes (2008) as

$F_{\mathrm{fm}}=C_{\mathrm{fm}} \frac{\rho}{2} L 2 y_{\mathrm{w}} v^{2}$,

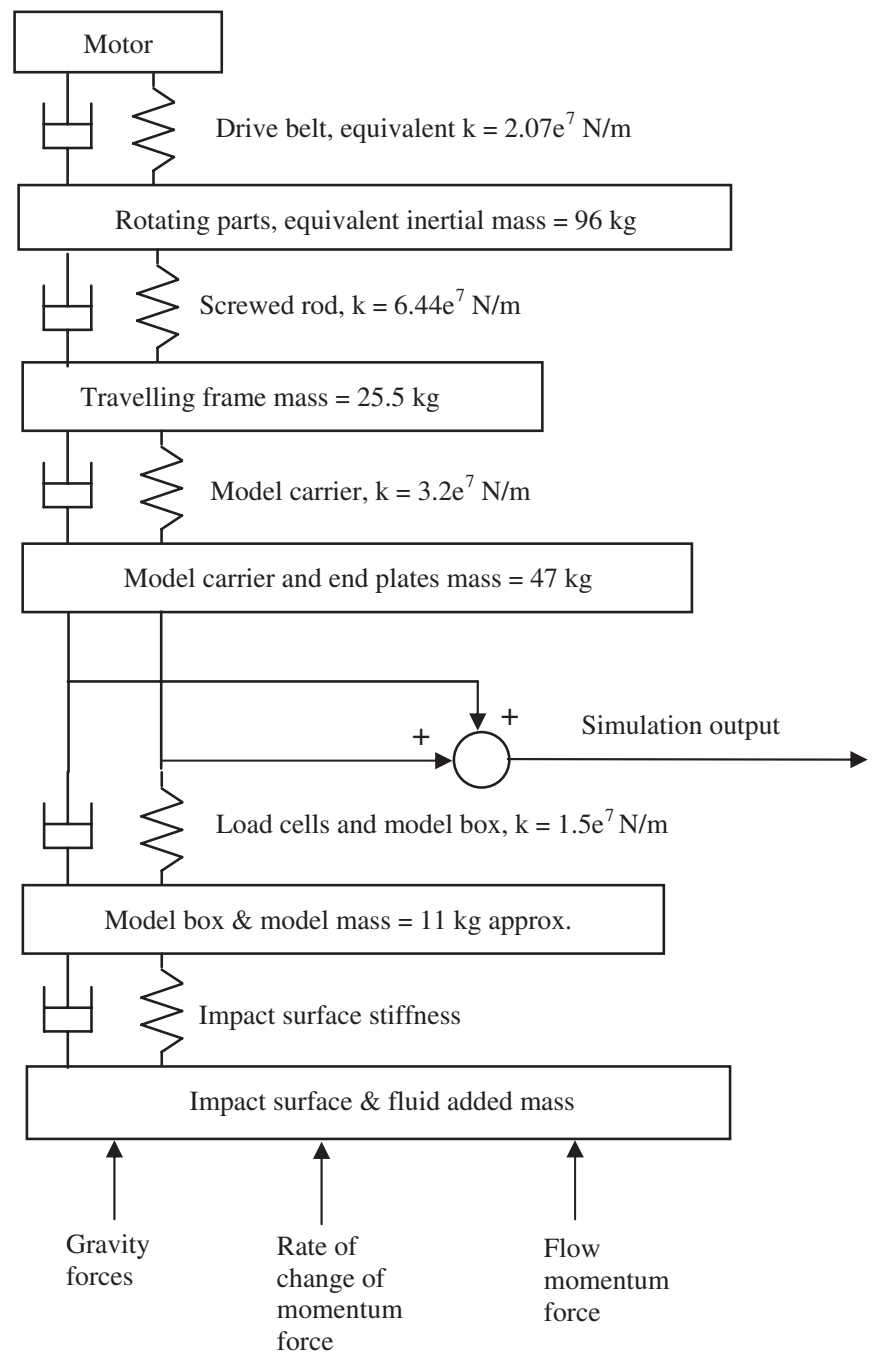

Fig. 9. Mathematical model. where $v$ is the vertical water entry velocity and the maximum value of $y_{\mathrm{w}}$ is $B / 2$. Values of the force coefficient $C_{\mathrm{fm}}$ (Fig. 13) were set in the simulation to match the experimental asymptotic value of the hydrodynamic entry force at large immersions where, it is assumed, the flow momentum drag is the only significant hydrodynamic force effect. At large deadrise angles, the maximum immersion of the test sections limited the value of $z / d$ that could be achieved to about 1.5-2.0 and at these values the residual gravity was still a significant force effect and influenced the estimates of the flow momentum drag. Given the large amount of noise in the force signal, it was not possible to determine whether there was any variation of the flow momentum drag with the entry speed, so just a single value was estimated for each deadrise angle wedge section. The CFD results of Fairlie-Clarke and Tveitnes (2008) are also shown in the figure.

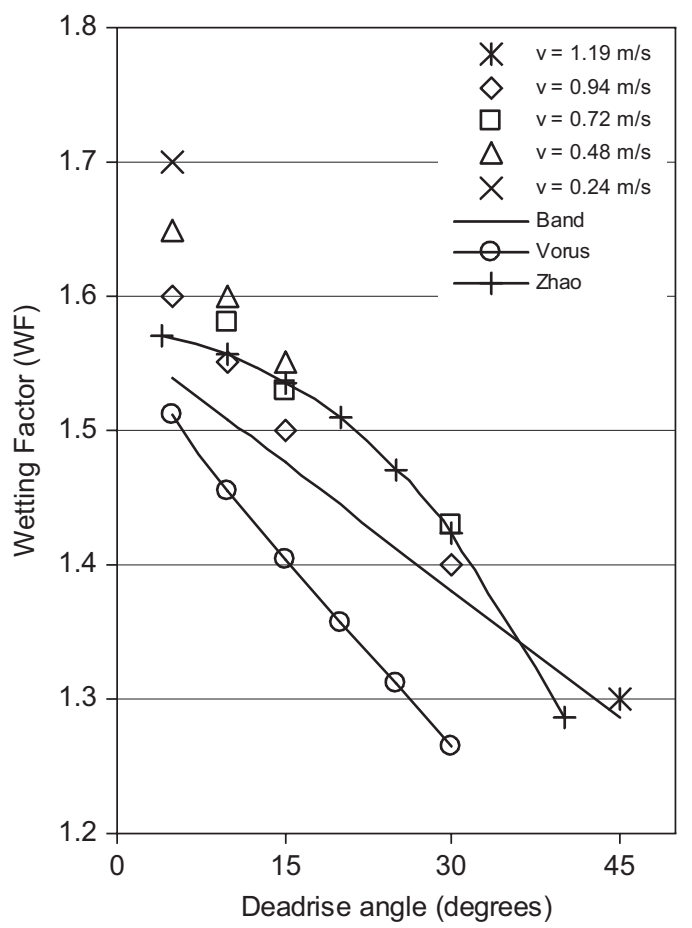

Fig. 11. Wetting factors.

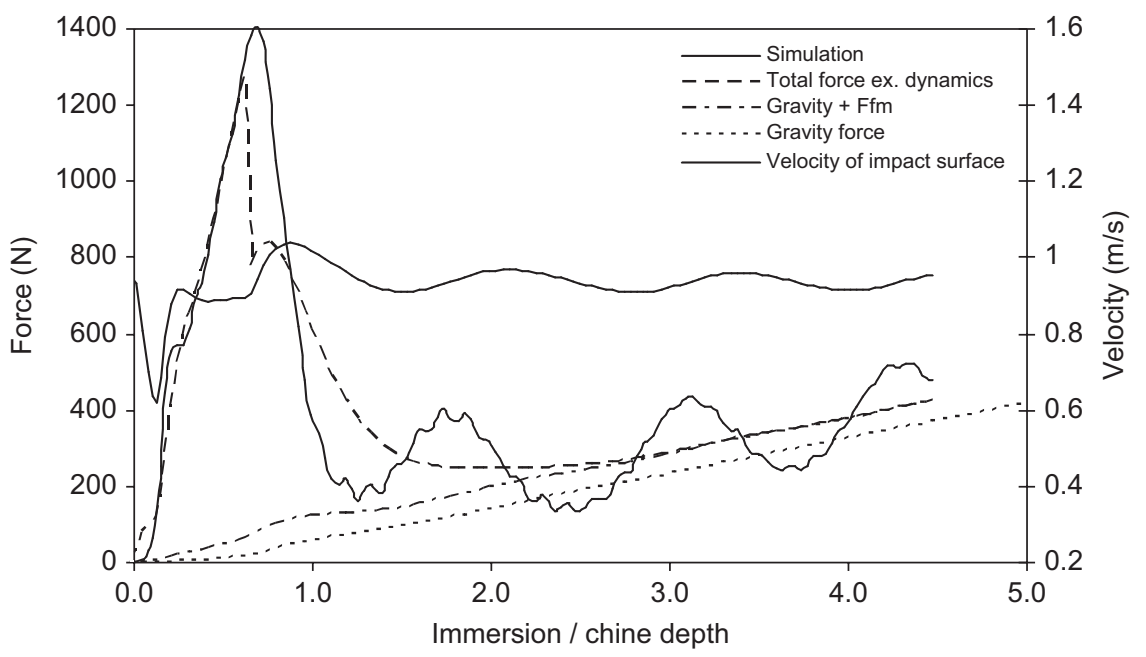

Fig. 10. Simulation force components. 


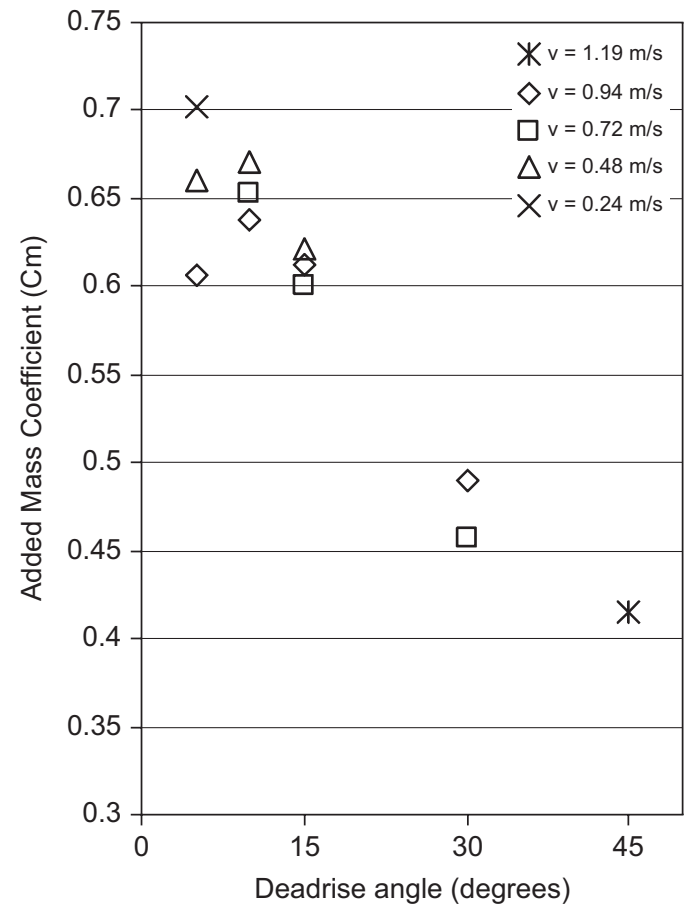

Fig. 12. Chine dry added mass coefficients $C_{\mathrm{m}}$.

Table 3

Residual gravity constants

\begin{tabular}{|c|c|c|c|c|c|}
\hline & \multicolumn{5}{|c|}{ Deadrise angle } \\
\hline & $5^{\circ}$ & $10^{\circ}$ & $15^{\circ}$ & $30^{\circ}$ & $45^{\circ}$ \\
\hline$k_{1}$ (experiment) & 0.25 & 0.2 & 0.15 & 0.1 & 0.1 \\
\hline$k_{1}\left(\mathrm{CFD}^{\mathrm{a}}\right)$ & 0.4 & 0.3 & 0.3 & 0.275 & 0.215 \\
\hline$k_{2}\left(\mathrm{CFD}^{\mathrm{a}}\right)$ & 2.0 & 3.0 & 3.3 & 3.5 & 2.0 \\
\hline
\end{tabular}

${ }^{\text {a }}$ Fairlie-Clarke and Tveitnes (2008).

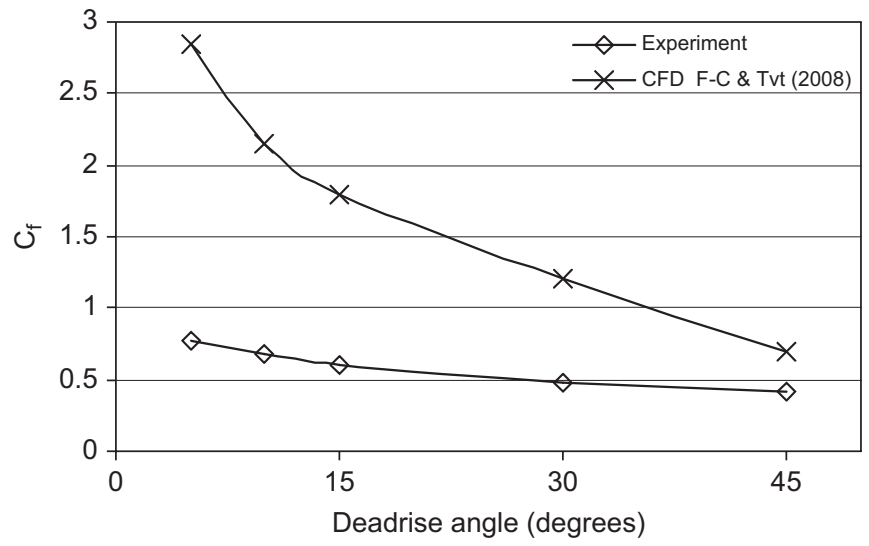

Fig. 13. Flow momentum drag coefficients.

An alternative added mass coefficient $C_{\mathrm{my}}$ can be defined for use with the wedge section offset $y[=v t / \tan (\beta)]$ at the undisturbed water level. It is given by $C_{\mathrm{my}}=W F^{2} C_{\mathrm{m}}$ and the values derived from the simulation of the experiment are compared in Fig. 14 with some estimates from the literature and with the CFD results of Fairlie-Clarke and Tveitnes (2008).

The experimental hydrodynamic water entry forces do not drop to the level of the flow momentum drag force immediately after chine immersion but fall more slowly, reaching this level

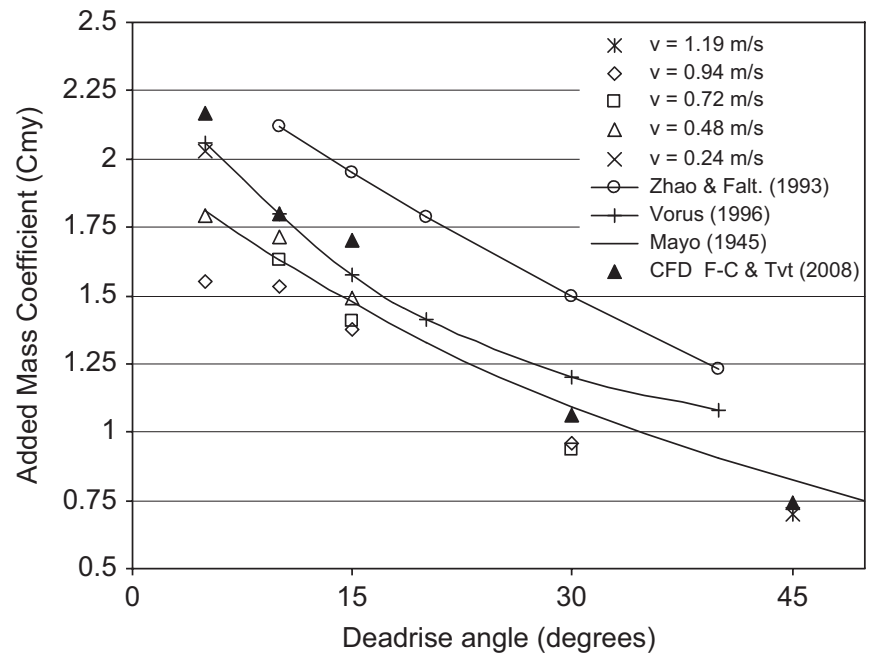

Fig. 14. Chine dry added mass coefficients based on section offset at undisturbed water level.

only when $z / d=2$ or more. This suggests that the added mass continues to rise, albeit more slowly, with increasing $z / d$ after chine immersion. A mathematical function was included in the simulation to represent this and its parameters were varied to give a good visual fit to the experimental data after the point of chine immersion. The resulting values of added mass over the whole range of $z / d$ are plotted for each deadrise angle in Fig. 15 in coefficient form where:

$C_{\mathrm{mb}}=\frac{m_{\mathrm{a}}}{\rho(\pi / 2) L(B / 2)^{2}}$.

The simulations allow an estimate of the experimental hydrodynamic force (i.e., rate of change of added mass and flow momentum forces) under true constant velocity conditions to be extracted from the test data for each test condition. These hydrodynamic force estimates are plotted for a water entry speed of $0.98 \mathrm{~m} / \mathrm{s}$ in Fig. 16 as $C_{\mathrm{fb}} \times \tan \beta$, where:

$C_{\mathrm{fb}}=\frac{\text { Force }}{(\rho / 2) L B v^{2}}$.

\subsection{Wet chine oscillation tests}

The estimated forces shown in Fig. 6 are based only on the hydrodynamic forces and do not include a simulation of the dynamics of the test equipment. The main hydrodynamic forces acting during wet chine constant acceleration oscillations are the added mass inertial force and the flow momentum drag force. The latter contributes a very small part of the total force and it is not possible to isolate it given the noise in the test recordings. It was therefore approximated by using a constant flow momentum drag force coefficient of 1.0. The added mass inertial force estimate was computed by differentiating the velocity as derived from the recorded speed of the motor and multiplying this by an estimated constant added mass that gave a good visual fit to the experimental data. This resulted in added mass coefficients $C_{\mathrm{mb}}$ of $1.2,1.0$ and 0.8 for the flat bottom, $15^{\circ}$ and $45^{\circ}$ wedge sections, respectively.

\subsection{Constant velocity water exit tests}

As the wedge exits the water, its added mass reduces. It is evident from the video images in Fig. 8 that much, if not all, of the 
a

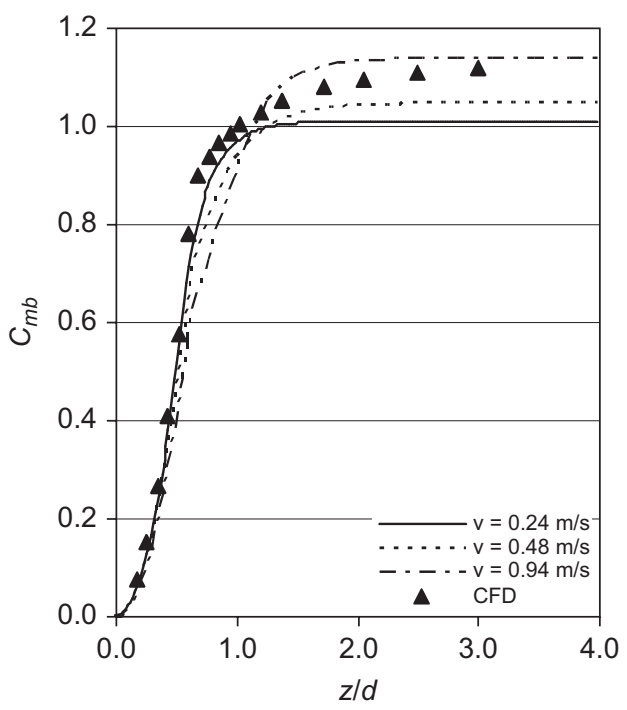

C

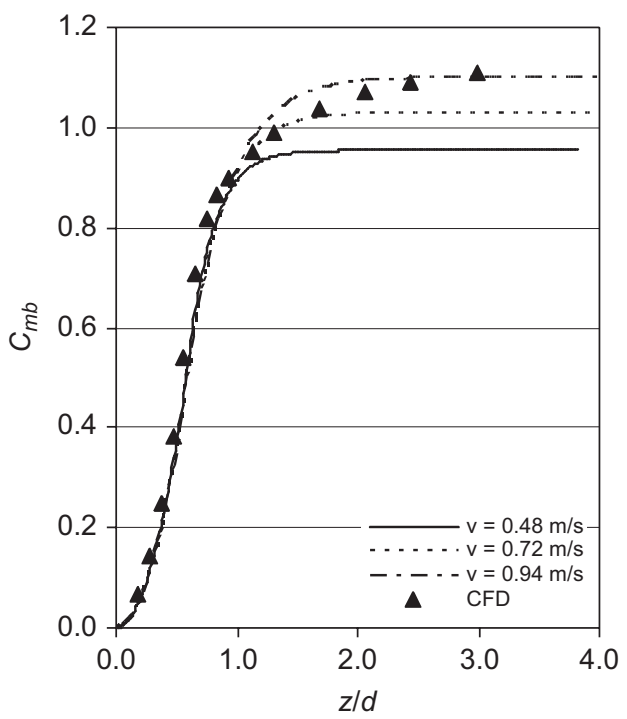

b

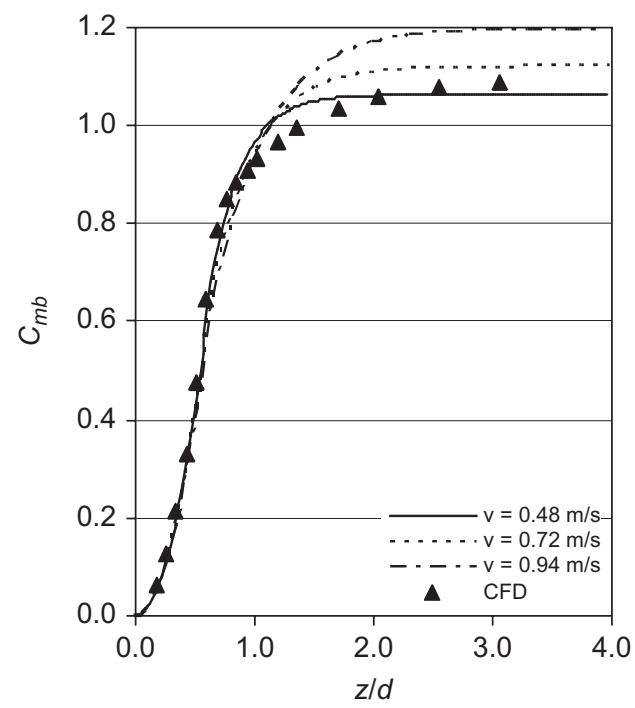

d

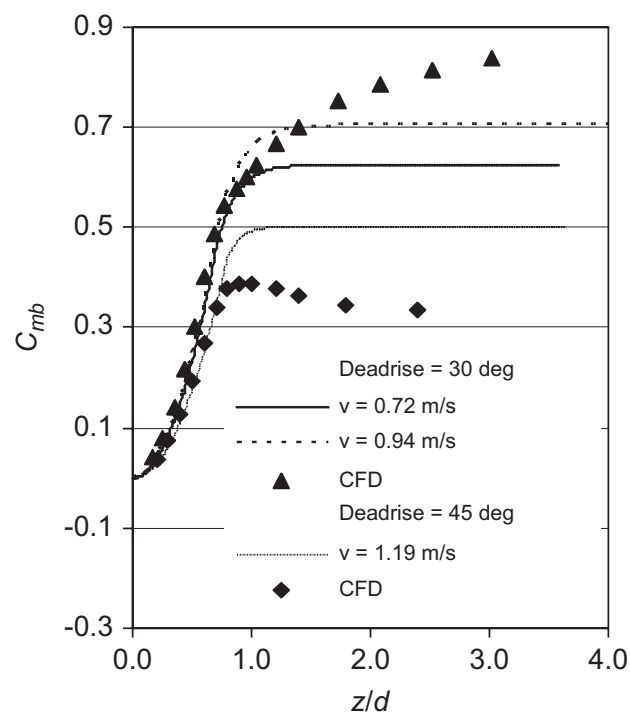

Fig. 15. Estimated added mass coefficients for all immersions, see Fairlie-Clarke and Tveitnes (2008) for CFD data. (a) $\beta=5^{\circ}$, (b) $\beta=10^{\circ}$, (c) $\beta=15^{\circ}$, (d) $\beta=30^{\circ}$ and $45^{\circ}$.

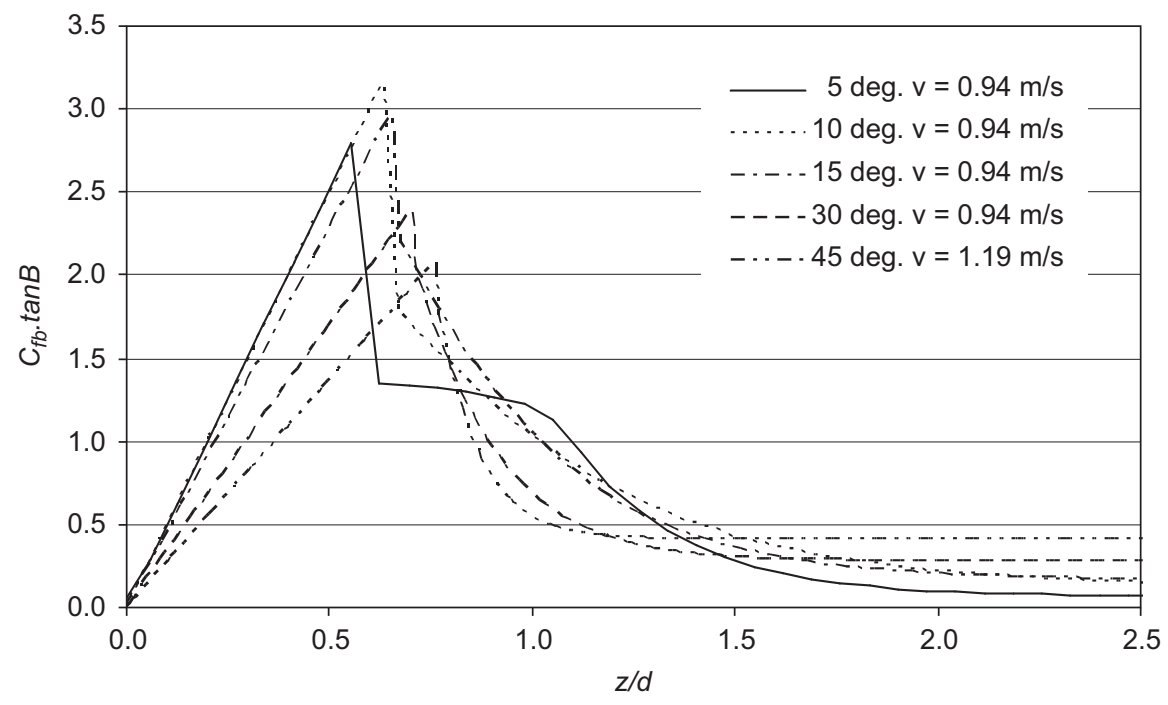

Fig. 16. Estimated experimental hydrodynamic entry force coefficients. 
Table 4

Drag coefficients during water exit

\begin{tabular}{lllll}
\hline \multicolumn{5}{l}{ Deadrise angle } \\
\cline { 2 - 5 } & $10^{\circ}$ & $15^{\circ}$ & $30^{\circ}$ & $45^{\circ}$ \\
\hline At $z / d>$ & 2.0 & 1.5 & 1.2 & 1.0 \\
$C_{\mathrm{ex}}=$ & 1.2 & 1.1 & 1.3 & 1.0 \\
At $z / d=0, C_{\mathrm{ex}}=$ & 0.5 & 0.3 & 0.5 & 0.3 \\
\hline
\end{tabular}

lost added mass momentum is expended in lifting the water against gravity rather than exerting an upward force on the rising wedge. The net exit force after subtracting buoyancy acts against the motion and is quite small; probably mainly drag. On this assumption, the force estimates shown in Fig. 7 were calculated as a drag force given by

$F_{\text {exit }}=C_{\text {ex }} \frac{\rho}{2} L 2 y v^{2}$,

where $y$ is the wedge section offset at the undisturbed water level (maximum value $B / 2$ ) and $C_{\mathrm{ex}}$ is the force coefficient, values for which were estimated to provide a good visual fit to the experimental data. $C_{\mathrm{ex}}$ was taken as constant above a given value of $z / d$ and then reduced linearly to a lower value at $z / d=0$, as given in Table 4 .

\section{Discussion}

\subsection{Test rig performance and analysis}

The purpose of the test rig was to achieve controlled velocity water entry, oscillations and exits while holding the test section steady, to simulate two-dimensional flow conditions and to accurately record the water entry forces.

The test rig's velocity control system had a demanding task to maintain constant velocity during the water entry tests because of the rapid increase in the dry chines entry force. The maximum variations in the velocity derived from the measured motor speed are given in Table 5 and fall within, or close to, the target of $1 \%$. The actual entry velocity of the impact surface was not measured, but it was estimated in the simulations of the dynamics of the system. In these, the dip in velocity on initial entry varied from $4 \%$ with the $30^{\circ}$ and $45^{\circ}$ wedge sections up to $35 \%$ during the fastest entry with the $5^{\circ}$ wedge section. Maximum oscillations in velocity after initial entry ranged from $\pm 1.6 \%$ at the large deadrise angle sections up to $\pm 11 \%$ with the $5^{\circ}$ wedge section.

The vertical position of the wedge surface was estimated by integration of the motor speed. The initial entry event provided a position check, but this was not completely reliable because of dynamics in the recorded force due to the downward acceleration of the section stopping just before water entry. This was most significant for the $30^{\circ}$ and $45^{\circ}$ wedge sections because of the higher accelerations needed to get these sections up to speed in the space available. A small lag was added to some of the experimental results to get a good fit with the simulation data immediately after water entry. This was implemented as an increment to the $z / d$ values of up to 0.012 .

The repeatability of the entry force measurements ranged from $1 \%$ to $3 \%$ of the peak force. The accuracy of the instrumentation was well within this range so the differences were likely to be mainly due to small variations in speed and position of the model. A good record of the initial rise in entry force is most important in predicting the added mass coefficient and WF. Fig. 4(a) shows that the fastest change in force occurs as the force reduces just after
Table 5

Maximum motor speed variation during water entry tests

\begin{tabular}{llllll}
\hline Velocity (m/s) & \multicolumn{5}{l}{ Deadrise angle (\%) } \\
\cline { 2 - 5 } & $5^{\circ}$ & $10^{\circ}$ & $15^{\circ}$ & $30^{\circ}$ & $45^{\circ}$ \\
\hline 0.24 & \pm 0.4 & & & & \\
0.48 & \pm 0.6 & \pm 0.3 & \pm 0.2 & & \\
0.72 & & \pm 0.4 & \pm 0.7 & \pm 0.7 & \\
0.94 & \pm 0.3 & \pm 0.4 & \pm 0.3 & \pm 0.3 & \\
1.19 & & & & & \pm 1.2 \\
\hline
\end{tabular}

chine wetting, and this demonstrates that the load cell response is more than adequate to record the initial rise in entry force. The sample time is a little slow for the rate of change in force in this figure, but given the drop in force between the peak and the next sample point, it seems unlikely that the peak could be much higher than indicated.

The video images in Figs. 5 and 8 show that the water surface was not disturbed beyond the end plates and indicate that a good approximation to two-dimensional flow was achieved. However, it can be seen in Fig. 5 that some water is forced up between the side of the model and the Perspex end plates with the $5^{\circ}, 10^{\circ}$ and $15^{\circ}$ deadrise angle sections, so two-dimensional flow conditions were not ideally achieved. This flow was very much less than the flow in the water jet, so the effect will have been much less than the flow momentum force and is estimated to be not more than about $0.2 \%$ of the maximum force.

The level of dynamic noise experienced during the tests was disappointingly high and affected the accuracy with which the hydrodynamic forces could be extracted from the test recordings. Sources of the dynamic noise included the cessation of acceleration of the test sections just before water entry, the dynamics of the structure and components, and flexure of the impact surface. The effect of these identified dynamics of the system was examined using the simulation described in Section 5 and this showed that the magnitude of the dynamic noise experienced during the experiments could be explained by the dynamics of the test equipment, and in particular by the flexing of the impact surface of the models. However, the dynamics in the experiment were more complex than explained by the simulation since the model of the impact surface was simplified and hydroelastic effects and lateral vibrations were not included.

It is likely that hydroelasticity had some effect on the experiment results at the lower deadrise angles. During the initial dry chine phase of entry, the impact surface will have deformed into a concave shape resulting in an effective increase in the deadrise angle and reduction in the section width below the chine. From the simulation, the mean deformation for the $5^{\circ}$ wedge section at $0.94 \mathrm{~m} / \mathrm{s}$ entry velocity would cause the effective deadrise angle to increase by a little over $1^{\circ}$ at the keel, and a maximum reduction in section width of about $30 \mathrm{~mm}$.

Determining the parameter values to fit the simulations was not an exact exercise since a similar quality of fit could be obtained with different sets of values. The range of these values is indicated in the following sections that discuss each parameter.

\subsection{Wetting factor}

The wetting factor was calculated as the ratio of the chine depth to the immersion depth $(d / z)$ at the point where similarity conditions break down during water entry of the wedge. The results (Fig. 11) show that $W F$ reduces approximately linearly with increasing deadrise angle. The values of $W F$ are lower at the higher 
water entry velocities. This is unexpected but may be due to two experimental effects. First, there is a hydroelastic effect due to the reduced half width of the wedge section at $0<z / d<1.0$ causing chine wetting to be delayed and giving an apparent reduction in $W F$. The second, but probably lesser effect is that the twodimensional flow conditions were compromised by some flow being forced between the end plates and the model section. This flow would have been greater at the higher velocities when water pressures were higher. The range of the estimates of WF from the simulations is less than $\pm 2.5 \%$.

The closest theoretical fits to these results are those given by Zhao and Faltinsen (1993) and by Band, as described by Payne (1993). The results confirm quite positively that $W F$ reduces with increasing deadrise angle.

\subsection{Flow momentum drag}

The estimates of flow momentum drag coefficients $C_{\mathrm{fm}}$ (Fig. 13) give credible values. Hoerner (1965) gives drag coefficient $C_{\mathrm{d}}=2.0$ for a submerged flat plate perpendicular to a two-dimensional flow, reducing to about 1.5 for a $45^{\circ}$ wedge. These values reduce by about a half if the plate has a body extending a distance twice its width or more down stream.

The values of $C_{\mathrm{fm}}$ obtained from the CFD simulations of FairlieClarke and Tveitnes (2008) are quite a lot higher than those estimated from the current experiments, especially at low deadrise angles. The experimental results are considered to provide the more reliable prediction of $C_{\mathrm{fm}}$ since they were estimated from the results at deep immersion where the hydrostatic force, which was the only other main force effect, could be reliably calculated. Also, the experimental results show good repeatability. The CFD results seem to be unreasonably high at low deadrise angles and this may be due to the difficulty of setting a grid around the chine line that enables accurate representation of the flow in this region.

\subsection{Added mass}

The added mass coefficients shown in Figs. 12 and 14 were estimated from the forces recorded during the dry chines phase of water entry when similarity conditions exist and the coefficients are expected to be constant at a particular deadrise angle. In Fig. 12, where the added mass coefficients are used with the wetted width of the sections, this is largely the case apart from the $5^{\circ}$ wedge sections. There is some scatter of the results at different velocities but there is no definite trend. In Fig. 14, where the added mass coefficients are used with the width of the sections at the undisturbed water level, there is a definite trend toward higher added mass coefficients for the lower water entry velocities, but this arises mainly because the wetting factors are higher at the lower velocities and may be entirely a consequence of hydroelastic effects.

There is a marked fall off in the added mass coefficients at low deadrise angles and this follows a similar pattern at both 0.94 and $0.48 \mathrm{~m} / \mathrm{s}$ entry velocities. This is a common feature of experimental results in the literature and it is likely that some physical effect not accounted for in the simulation is significant. An air cushion effect is one candidate, but Chuang (1967) shows that this is unlikely to be significant at deadrise angles greater than about $3^{\circ}$, although the use of end plates may increase any air cushion effect. Some of the effect may be due to three-dimensional flows that are greater at the higher entry velocities when the water pressures are higher. Hydroelasticity may also have an effect, but because the sidewall of the model is stiff, the chine line will not have deflected much and the effect may not be large, although it is difficult to predict.

The range of the estimates of dry chine added mass from the simulation was up to $\pm 5 \%$.
The added mass estimates from the literature that are shown in Fig. 14 are all based on the assumption that the entry force is solely due to the rate of change of added mass, whereas the experiment values and the CFD values are calculated after first removing the estimated flow momentum drag force. This reduces the added mass coefficients by about 2-5\%. The experimental results are around 25\% lower than the numerical results of Zhao and Faltinsen (1993), but closer to those of Vorus (1996). The theoretical estimates assume that the water entry velocity is infinite, while the experiments are performed at finite velocities and some gravitational effects will be present, though they are small. The closest fit is with Mayo (1945), whose empirical formula was based on experiments with flying boat floats, and with the CFD results, which are about $10 \%$ higher than the highest experiment values but have a similar variation with deadrise angle.

Fig. 15 shows that the added mass continues to rise after chines immersion to a considerably greater value than at the point when the chines become wetted and the entry force reaches its peak value. This rise is about $20 \%$ with the $45^{\circ}$ wedge section up to about $80 \%$ with the $5^{\circ}$ and $10^{\circ}$ wedge sections. The wet chine added mass values were difficult to extract from the experimental data because of the high dynamic noise after chine immersion and lack of exactness in the simulation. The range of the estimates of wet chine added mass was about $\pm 10 \%$, except for the $5^{\circ}$ wedge section test at $0.94 \mathrm{~m} / \mathrm{s}$ where the characteristics of the force curve for $0.67<z / d<3.0$ are different to all other tests and it was not possible to get as good a fit to the data and the range of estimates was nearer to $\pm 20 \%$.

This wet chine added mass is much larger than previously identified in the literature (Payne, 1981), but at all deadrise angles except $45^{\circ}$ it is consistent with the CFD simulations of FairlieClarke and Tveitnes (2008), also shown in Fig. 15. For the low deadrise angle sections, where there is a significant discontinuity in the flow at the chime, it increases the total added mass to the same order as was measured in the oscillation tests. The increase in added mass is speed dependent and it is likely that viscous flow effects at the chine are significant. With the $45^{\circ}$ wedge section, the oscillation test gave about $60 \%$ higher total added mass than the water entry test. There is a lot of scatter in the experimental results, but that cannot explain the large difference. There is no real discontinuity of flow at the chines during the water entry of the $45^{\circ}$ wedge section, so perhaps the difference arises because viscous flow is induced by the oscillations.

Fig. 16 shows the hydrodynamic entry force coefficient $C_{\mathrm{fb}}$ multiplied by $\tan (\beta)$ for the higher speed water entries as calculated using the estimated experimental values of added mass and flow momentum. The results provide a reasonably consistent set of data apart from the curve for the $5^{\circ}$ wedge section, which has a low peak force, reflecting the low dry chine added mass, and a hump in the mid-range of $z / d$ that reflects the increase in wet chine added mass in this region that was necessary to obtain a reasonable fit to the experimental data. There is no supporting evidence for this characteristic of the curve and it requires further investigation.

\subsection{Gravity effects}

In addition to the hydrostatic forces, gravity can affect the water entry forces by changing the flow regime, by changing the wetting factor and because work must be done to lift the water in the splash up zone and in the spray above the undisturbed water level. Takemoto et al. (2000) presented a theory for calculating the threshold velocity above which gravity does not affect the flow significantly. This theory predicts the threshold velocities for the current experiment conditions as less than $0.5 \mathrm{~m} / \mathrm{s}$. However, 
Takemoto et al. used free-fall tests to verify their theory and it is possible that thresholds during constant velocity entry may be different. Thus, it is possible that residual gravity effects were important in these experiments.

Gravity will act to reduce the wetting factor at low entry velocities, but in fact the opposite was found (see Section 6.2) so any gravity effect has been overridden by some other effect. At the entry velocities used in the experiments, the hydrodynamic forces are large compared with gravity forces during the dry chines phase of entry and it is only during the wet chines phase of entry that residual gravity effects might be discernable. The inclusion of some residual gravity force did improve the fit of the simulations to the experimental data. It also resulted in the estimated flow momentum drag force coefficients following the expected trend of reducing with increasing deadrise angles, whereas without the inclusion of residual gravity forces they increased at $30^{\circ}$ and $45^{\circ}$ deadrise angles.

The residual gravity force coefficients estimated from the experiment results can be calculated using Table 3 and have values about half of those obtained from the CFD simulations of Fairlie-Clarke and Tveitnes (2008). Even so, the maximum residual gravity force is still between $20 \%$ and $50 \%$ of the static buoyancy up to the chine line and can be a significant factor.

Although gravity did not appear to reduce the height of the water pile up at the entry velocities used in the experiments, at lower entry velocities the water pile up will be reduced and will tend to zero as the entry velocity tends to zero. The residual gravity force will therefore also tend to zero and must be velocity dependent, but the available data does not allow an estimate of this to be made.

\subsection{Water exit}

The water exit forces are quite low and it is unlikely that there is any significant added mass contribution to the force. Explaining the whole force by an estimated drag coefficient (Table 4) gives credible values for the coefficients. Part of the wedge surface remains wetted after the apex of the wedge rises above the undisturbed water level, but this does not result in any significant net force on the wedge.

\subsection{Further work}

The constant velocity water entry experiments have provided useful data for validation of the increasingly detailed theoretical and numerical results that are becoming available, and they show some interesting results. Many variables were involved in the simulations and it was possible to get similar levels of accuracy of fit to the experiment results with slightly different combinations of variable values, especially after the chines become immersed. The proportional contribution to the total force by the increase in added mass after chine immersion, by the flow momentum drag and by the residual gravity force cannot be determined exactly. Fairing across the different deadrise angles was used to improve the reliability of the predictions and the results presented do provide a credible representation of the main force effects, but further validation is required.

Further work should therefore be undertaken to improve the accuracy of the results. Measures should be taken to reduce the dynamic noise. In particular, the wedge impact surfaces should be made much stiffer. This should reduce the variation in velocity at the impact surface to less than $\pm 2.5 \%$ and enable much more accurate estimates of the wet chine added mass. Tracks should be fitted to guide the model carrier throughout its travel and a low stiffness seal should be fitted between the model and the end plates to prevent any end flow, but the force transmitted through the seal must be minimal. The velocity of the impact surface and the instant of water entry should be recorded. Tests should also be conducted over a greater range of entry velocities.

\section{Conclusions}

The experiments reported in the paper are believed to be the first to test the water entry of wedge-shaped sections at constant velocity. The experimental data provide a useful addition to the literature in that (1) force is plotted against chine immersion, rather than acceleration against time, (2) the force is recorded up to deep immersions where the added mass is no longer changing, (3) the velocity is held constant so that the instant of chine wetting is marked by a clear termination of similarity conditions in the force record. All this allows the different force effects to be more clearly isolated and, in particular, the changes in added mass after chine wetting to be quantified. This is important for planing craft predictions where estimates of added mass are needed for all immersion depths, and the new data also provide an aid to improving theoretical and numerical predictions of water entry under both constant velocity and free-fall conditions.

The results are in general consistent with empirical and theoretical results given in the literature, but reveal some important issues:

(1) The wetting factor is shown to be strongly dependent on the deadrise angle.

(2) The dry chine added mass is lower than theoretical predictions, particularly at low deadrise angles, but is consistent with other experimental results.

(3) The added mass is shown to continue to increase after chine immersion by up to $80 \%$ above the value at the point when the chines become wetted. This is a much larger increase than previously predicted in the literature.

(4) The maximum added mass measured during water entry was of the same order as measured by oscillation tests for the low deadrise angle wedge sections but some $40 \%$ lower for the $45^{\circ}$ wedge section.

(5) A flow momentum force is identified that is equivalent to a cross-flow drag force.

(6) Water exit forces are quantified and shown to oppose the motion and to be equivalent in magnitude to a drag force. The added mass momentum that is expended as the section exits the water acts to lift water above the surface and does to exert a force on the wedge section.

The test rig, as built, was subject to significant dynamic noise that limits the accuracy of the results, particularly after chine immersion.

\section{Acknowledgements}

The work reported in this paper draws largely on the postgraduate research studies of Tveitnes (2001), and the support of the departments of Mechanical Engineering and of Naval Architecture and Marine Engineering at the University of Glasgow is gratefully acknowledged.

\section{References}

Bereznitski, A., 2001. Slamming: the role of hydroelasticity. International Shipbuilding Progress 48 (4), 333-351.

Bisplinghoff, R.L., Doherty, C.S., 1952. Some studies of the impact of vee wedges on a water surface. Journal of the Franklin Institute 253, 547-560. 
Carcaterra, A., Ciappi, E., 2004. Hydrodynamic shock of elastic structures impacting on the water: theory and experiments. Journal of Sound and Vibration 271, 411-439.

Chuang, S.-L., 1967. Experiments on slamming of wedge shaped bodies. Journal of Ship Research 11, 190-198.

Fairlie-Clarke, A.C., Tveitnes, T., 2008. Momentum and gravity effects during the constant velocity water entry of wedge shaped sections. Ocean Engineering 35, 706-716.

Hoerner, S.F., 1965. Fluid-Dynamic Drag. Hoerner Fluid Dynamics, Brick Town, NJ, USA. Mayo, W.L., 1945. Analysis and Modification of Theory for Impact of Seaplanes on Water. TN1008, National Advisory Committee for Aeronautics, Washington, D.C.

Payne, P.R., 1981. The normal force on a flat planing plate, including low length to beam ratios. Ocean Engineering 8, 221-258.

Payne, P.R., 1993. The spray sheets produced during vertical wedge impact and steady planing. Ocean Engineering 20, 247-261.
Takemoto, H., Oka, M., Sakuma, M., 2000. Experiments of threshold velocity of water impact of wedges. Transactions of West Japan Society of Naval Architects $100,245-254$.

Tveitnes, T., 2001. Application of added mass theory in planing. University of Glasgow Thesis 12640 .

Vorus, W.S., 1996. A flat cylinder theory for vessel impact and steady planing resistance. Journal of Ship Research 40, 89-106.

Wagner, H., 1932. Über stoß und gleitvorgänge an der oberfläche von flüssigkeiten. Zeitschrift fur Angewandte Mathematik und Mechanik 12, 193-215.

Wu, G.X., Sun, H., He, Y.S., 2004. Numerical simulation and experimental study of water entry of a wedge in free fall motion. Journal of Fluids and Structures 19, 277-289.

Zhao, R., Faltinsen, O., 1993. Water entry of two-dimensional bodies. Journal of Fluid Mechanics 246, 593-612. 